\title{
LAS CALIFICACIONES DEL SABER JURÍDICO Y LA PRETENSIÓN DE RACIONALIDAD DEL DERECHO *
}

\author{
Jesús Vega \\ Universidad de Oviedo
}

RESUMEN. En este trabajo se analiza la pretensión de racionalidad del Derecho desde una perspectiva epistemológica. Para ello se parte de la distinción entre el estatuto interno de la racionalidad jurídica (relación entre el Derecho y la "ciencia jurídica») y su estatuto externo (relación entre racionalidad jurídica y otras racionalidades científicas). Tras hacer un recorrido histórico por las distintas calificaciones epistemológicas del saber jurídico, y examinar sus problemas, se introducen seis tesis acerca de la racionalidad jurídica en sus diferentes niveles, haciendo especial hincapié, por un lado, en su carácter práctico o «técnico» y la funcionalidad normativa del discurso dogmático (estatuto interno) y, por otro, en la vinculación necesaria con la idea de verdad y la racionalidad científica que se manifiesta en las instituciones de aplicación del Derecho (estatuto externo).

Palabras clave: Derecho, racionalidad práctica, ciencia, técnica jurídica, dogmática, verdad, prueba.

ABSTRACT. This paper attempts to analyze Law's claim to rationality from an epistemological perspective. For this purpose, the author firstly introduces the distinction between the internal statute of legal rationality (the relation between Law and «legal science») and its external one (the relation between legal rationality and other scientific rationalities). Secondly, he gives account of the different epistemological conceptions on legal knowledge along history as well as the problems implied herein. And finally, six theses on legal rationality at its different levels are introduced. These refer, on the one side, to the practical or «technical» character of that rationality and to the normative function of the legal science (internal statute); on the other, to the necessary connection between legal rationality and the concept of truth and thus with scientific rationality as shown in legal adjudication (external statute).

Key words: Law, practical rationality, science, legal technique, legal science, truth, evidence.

*Fecha de recepción: 27 de marzo de 2009. Fecha de aceptación: 30 de abril de 2009. 


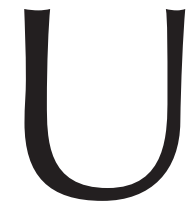

no de los temas centrales de la filosofía del Derecho es el análisis de la racionalidad jurídica. «Racionalidad» suele entenderse en un sentido justificativo, como un tipo de corrección o justicia, de carácter jurídico o moral. Aquí, sin embargo, me voy a referir a su sentido epistemológico, al que presupongo filosóficamente previo y condicionante del anterior. También ha sido usual plantear el problema (epistemológico) de la racionalidad jurídica como el problema de si cabe una racionalidad científica en el Derecho. Ambas cuestiones son diferentes, pero en este trabajo sostendré que se hallan intrínsecamente conectadas y que una respuesta fundada a la primera exige haber respondido a la segunda. Es decir, que la pretensión de racionalidad del Derecho está íntimamente vinculada con el problema de la racionalidad científica del Derecho y que ello condiciona a su vez la pretensión de corrección o justicia del Derecho.

Para mostrarlo distinguiré entre el «estatuto interno» de la racionalidad jurídica, relativo a qué tipo de racionalidad estructura internamente al Derecho como institución, y su «estatuto externo», referente a las relaciones que la racionalidad jurídica mantiene con otras formas de racionalidad extrajurídicas. Ambas perspectivas se codeterminan. Así, en esta última (estatuto externo) surge la cuestión de si el Derecho es o no una ciencia, al clasificarlo comparativamente con otras disciplinas de acuerdo con alguna teoría general epistemológica. Aquí haré un recorrido histórico de esta perspectiva, para mostrar cómo las calificaciones epistemológicas que ha recibido la racionalidad jurídica, pese a haber sido siempre problemáticas (es decir, pese a no haber reconocido al Derecho dentro de las formas canónicas de racionalidad científica: es «el problema de la ciencia jurídica»), son sin embargo las que han suministrado el marco conceptual necesario para su definición y perfilado epistemológico respecto de las demás formas de racionalidad, contribuyendo con ello a fijar las notas distintivas que caracterizan a su «estatuto interno». Inversamente, si partimos de reconocer la existencia de una «pretensión de racionalidad» interna al Derecho, no ya una pretensión de justicia o corrección (ALEXY) o una pretensión de autoridad (RAZ), pero muy relacionada con éstas, es necesario reconocer también que los términos en que ella pueda ser definida están vinculados de una manera esencial con las relaciones (problemáticas) que el Derecho mantiene con la racionalidad científica (no sólo con la «ciencia jurídica» o dogmática, sino sobre todo con las ciencias no jurídicas), lo que de nuevo nos devuelve al estatuto externo.

Para desarrollar estas ideas seguiré el siguiente esquema expositivo. En primer lugar, introduciré cinco premisas previas orientadas a acotar los términos generales de la problemática de la racionalidad jurídica y despejar algunas suposiciones y percepciones comunes sobre el asunto y su planteamiento como tal «problema» (I) A continuación seguirá lo que podría llamarse una «historia epistemológica» del asunto, es decir, un recorrido sumario por lo que se ha entendido (y se entiende) por «racionalidad» y «ciencia del Derecho» a lo largo de los distintos modelos epistemológicos históricamente vigentes (II) Por último, como conclusión del análisis, plantearé seis tesis sobre el alcance de la pretensión de racionalidad del Derecho (III). 
Éstas son las premisas que, en mi opinión, deberían ser asumidas por cualquier análisis del problema del estatuto interno y externo de la racionalidad del Derecho:

1. $\left.{ }^{a}\right)$ Si el problema de la racionalidad jurídica es realmente un problema filosófico, entonces no sólo tiene una dimensión epistemológica, sino también ontológica. Esto significa que desborda lo que habitualmente se entiende como «epistemología jurídica» (análisis del conocimiento del y sobre el Derecho) para afectar también a los atributos ontológicos que puedan predicarse en general del mismo (análisis del tipo de realidad que envuelve el Derecho). En efecto, las tesis y aseveraciones sobre el Derecho a las que se llegue en el plano epistemológico tienen un impacto inmediato en (y están condicionadas por) tesis y aseveraciones relativas al rango ontológico de la categoría jurídica, es decir, a su constitución y estructura interna, al tipo de implantación que tiene dicha categoría respecto del dominio de objetos de que consta o a que se refiere, a su relación con otras categorías, a su grado de autonomía o dependencia respecto de éstas, etcétera. Por ejemplo, la entidad ontológica que atribuimos al Derecho (no sólo su «discurso» o «conocimiento») no es la misma si sostenemos que es una ciencia, que si sostenemos que es una técnica, una práctica, un discurso lingüístico o una ideología «superestructural» enmascaradora de la realidad social. Tampoco sus relaciones de proximidad con otras categorías colindantes, como las morales o políticas, son las mismas.

2. ${ }^{a}$ El análisis filosófico de la racionalidad jurídica constituye una crítica de las concepciones que conforman el discurso jurídico mismo (es decir, las autoconcepciones de los juristas). El problema de la racionalidad no es percibido generalmente como tal problema dentro del propio Derecho. Esto significa sencillamente que el Derecho no es una disciplina en busca de un «método racional», que persiga —en las célebres palabras de KANT - dar con «el seguro sendero de la ciencia», ni una disciplina que se halle en trance de «crisis de racionalidad» o de «cientificidad», sino una disciplina que cree muy bien asentada su metodología, la cual posee para sus cultivadores plena racionalidad y operatividad en su ámbito. La mejor prueba de ello es que institucionalmente el Derecho ha asumido el nombre de «ciencia», que es la expresión del saber racional más riguroso. El jurista contemporáneo habla de la «ciencia del Derecho» para referirse ya al saber jurídico general en que ha sido formado, ya a sus distintas especialidades (civil, penal, etc.), las cuales son llamadas «ciencias jurídicas». Las investigaciones de los teóricos de estas diferentes disciplinas son consideradas habitualmente como investigaciones de contenido científico homologables a otras del ámbito universitario (p. ej., como es el caso en España, en el área de las «ciencias jurídico-sociales»), e incluso la propia Facultad de Derecho recibe en algunos países —así en Alemania, pero también entre nosotros - la denominación de Facultad de «Ciencia/s Jurídica/s». Así pues, para el jurista no ofrece problema alguno la conceptualización de su disciplina como científica o racional, aun asumiendo - como también hace sin reparo- que no se trate de una ciencia al estilo experimental o matemático. Y lo mismo cabe decir de la autoconcepción de sus instituciones prácticas, legislativas o jurisdiccionales, a las que aunque no se califique como científicas sí se considera como gobernadas por una metodología racional cerrada dotada de reglas propias perfectamente precisas y asentadas. 
$\mathrm{El}$ «problema» de la racionalidad jurídica sólo surge como tal cuando esta concepción que de sí mismo tiene el método jurídico es sometida a algún tipo de valoración crítica desde parámetros externos. Las polémicas metodológicas son más filosóficas que propiamente jurídicas (lo cual no quiere decir obviamente que no influyan en la práctica metódica real, pero sí que consisten en críticas en segundo nivel respecto de ésta). Así sucede, por ejemplo, con la actual discusión del «constitucionalismo» frente al «positivismo», que es una puesta en cuestión de las pautas que rigen la racionalidad de la producción y la aplicación del Derecho en el Estado legal de Derecho desde su implantación (p. ej., la transición desde las reglas a los principios o razones subyacentes, de la subsunción a la ponderación); o también la polémica formalismo/antiformalismo de principios del siglo $\mathrm{Xx}$, cuando se cuestionaron las consecuencias que se derivaban del modelo decimonónico del «legislador racional» para la aplicación del Derecho; o el desplazamiento que se produjo posteriormente desde el «método» a la «argumentación» en la justificación de la racionalidad de las decisiones jurisdiccionales; o la controversia acerca de la codificación y el «legislador racional» que dio lugar al propio legalismo dos siglos antes. Todas estas son polémicas relativas al estatuto interno de la racionalidad jurídica, pero demuestran que no son solamente internas (metódicas) en el hecho que todas ellas involucran un replanteamiento de qué es el Derecho (una concepción filosófica) y responden a transformaciones históricas efectivas de las estructuras jurídico-políticas y en general morales. De manera análoga, el «problema de la ciencia jurídica» sólo puede plantearse una vez que se establece una comparación filosófica (epistemológica) con otras ciencias, desde las ciencias naturales y formales hasta las restantes disciplinas sociales. Es entonces cuando el carácter científico del Derecho puede ser impugnado o discutido (o bien reivindicado). Como veremos, los esquemas de comprensión de la racionalidad interna del Derecho siempre han sido dependientes de las calificaciones epistemológicas externas (tanto de signo positivo como negativo o «descalificaciones»), y en este sentido su naturaleza problemática es una constante histórica, no un fenómeno moderno (ligado, p. ej., al sonoro nombre de VON KIRCHMANN).

3. ${ }^{a}$ La crítica filosófica de la racionalidad jurídica, como cualquier otra crítica, tiene que llevarse a cabo desde algún criterio: es necesario, pues, contar con un modelo epistemológico o una teoría general de la ciencia tal que permita determinar cuál es el lugar que ocupa el Derecho dentro del conjunto de los sistemas de racionalidad. Si una de las tareas centrales de la filosofía jurídica es proporcionar un «mapa» de la racionalidad jurídica, ello presupone un mapa filosófico de la racionalidad en general, en ausencia del cual se esfuma el problema de la racionalidad o la cientificidad del Derecho: como señala NEUMANN, se convierte en un «problema aparente». Y a la inversa: cualquier respuesta que se dé a la cuestión, añade el mismo autor, no constituye solamente una afirmación sobre la racionalidad jurídica — - p. ej., sobre su carácter científico o no científico - sino también una afirmación sobre la idea general de racionalidad o ciencia que se está manejando (Neumann, 1992: p. 352). De nuevo cabe decir que no es tanto un problema del Derecho cuanto de la filosofía de la ciencia que profesa el crítico. Por otra parte, de aquí se deduce que la tarea de establecer qué tipo de racionalidad es característica del Derecho constituye una tarea comparativa, clasificatoria, conforme a ese modelo general. No es una cuestión de «todo o nada», de sí o no, puesto que no se trata tanto de decidir si es o no racional, cuanto de cómo lo es 
comparándola con alguna otra disciplina o ciencia en particular o estableciendo sus relaciones con otras formas de racionalidad. A la pregunta de si el Derecho es racional o si es ciencia habría que responder antes que nada con otra pregunta: ¿comparado con qué? Es preciso desechar un enfoque absolutista en pro de uno relativo o posicional que implica valoraciones muy diferentes respecto de otras racionalidades y otras disciplinas, científicas o no científicas. Por ejemplo, y para decirlo rápidamente, nuestro pronunciamiento epistemológico acerca del estatuto racional de la dogmática penal será muy diferente si el término de comparación es la magia, la ordalía, la criminología forense, la sociología o la bioquímica.

4. ${ }^{\text {a) }}$ Pero tampoco tienen cabida el relativismo ni el escepticismo epistemológicos al respecto. Tales posiciones vienen a sostener que la naturaleza racional o cognoscitiva del Derecho es un pseudoproblema carente de importancia filosófica. Unas veces por considerarlo un asunto puramente ideológico-gremial relativo al prestigio corporativo y social del oficio jurídico o de valor meramente justificativo respecto del aparato coactivo del Derecho (CALSAMiglia, 1986: p. 67). Otras veces por creer que las etiquetas «racionalidad»o «ciencia» son puramente nominales, al responder a un uso emotivo del lenguaje o a simples estipulaciones lingüísticas (NINO, 1974: p. 114). Estamos, sin embargo, ante un verdadero problema filosófico cuya importancia va mucho más allá del mero uso ideológico o convencional de la etiqueta «racionalidad» o «ciencia». En realidad es este mismo uso - en tanto ya está establecido: premisa 2. ${ }^{\text {}}$ - el que demuestra dicha importancia. Debemos partir de él para tratar de ver cuál es su justificación y determinar hasta dónde puede llegar el uso del concepto de «ciencia del Derecho» como indicativo de una de las dimensiones de la racionalidad jurídica o cuál es el significado efectivo de la calificación de ésta en su conjunto como racionalidad «práctica» o «teórica». Esto implica no eludir sino afrontar el carácter problemático que estas etiquetas tienen y siempre han tenido. O sea, implica un planteamiento epistemológico. Así, un tipo de racionalidad que es calificada de «dogmática» sólo puede ser visto como una contradictio in terminis cuando se adoptan como punto de comparación otras formas de racionalidad «no dogmáticas»; un saber «práctico» sólo puede estar definido respecto de otros saberes «teóricos», uno «normativo» por contraste con otro «empírico», etc. Como queda dicho, de la respuesta que se dé a estas cuestiones dependerá nuestro entendimiento del Derecho mismo, nuestra teoría filosófica del Derecho, y por eso no es materia de mera convención o consenso, como tampoco lo es, pongamos por caso, llamar o no racional y científica a la astronomía (frente a la astrología) o a la medicina (frente al curanderismo). El relativismo o el escepticismo, en suma, sólo tienen cabida en ausencia de criterios epistemológicos sólidos. Pero, además, y dado que ambas perspectivas se interconectan, el escepticismo sobre la cientificidad del Derecho corre el riesgo de ser, a fin de cuentas, un escepticismo sobre el Derecho mismo, es decir, sobre su racionalidad interna. Con ello pasa a ser un escepticismo no ya epistémico, sino práctico, pues anula la propia pretensión de racionalidad del Derecho, y por tanto su pretensión de corrección, y esta negación es pragmáticamente autocontradictoria ${ }^{1}$.

${ }^{1}$ Cfr. Alexy, 1989: pp. 134, 318; 1993: p. 45; AtiEnZA, 1996: pp. 13 y ss. Por ejemplo, y para adelantar cosas de las que luego trataremos, impugnar la presencia de la idea de verdad en el Derecho impide al escéptico diferenciar epistémicamente (y, por tanto, moralmente) entre someterse a un proceso judicial con todas las garantías y un sistema de ordalía, entre una prueba criminológica y la práctica de la tortura como medio de obtención de la verdad, etc. 
5. a) Por último, la crítica del conocimiento y de la racionalidad jurídica no puede ser confundida con algo así como una crítica total o destructiva del Derecho. Esta prevención es especialmente pertinente en relación con la visceralidad con que entre los juristas suelen ser recibidas las descalificaciones epistemológicas de la idea de «ciencia jurídica». Asumiendo que ello constituye una descalificación del Derecho mismo, una especie de «abolición intelectual» del mismo, se ha concluido - pidiendo el principio- que puesto que la ciencia del Derecho (o, por extensión el Derecho mismo) es socialmente útil, necesaria y hasta imprescindible, entonces tiene que ser científica ${ }^{2}$. Poner en entredicho la cientificidad del Derecho no equivale a una apreciación condenatoria de su «dignidad» o de su utilidad social y menos todavía a una mengua de su importancia social. Como apunta LLEWELLYN (1941: p. 22), «el conocimiento no tiene que ser científico para ser útil e importante». La crítica epistemológica no pretende desautorizar ni menoscabar el valor y sistematicidad del saber jurídico ni desterrar el uso del término «ciencia» - algo bastante ocioso en una cultura científica como la nuestra en donde, como hemos dicho, prácticamente toda actividad académica reclama el nomen de ciencia-, sino simplemente describir y clasificar la estructura de ese saber particular para fijar su posición entre todos los demás, y de esa forma contribuir a aclarar hasta dónde puede llegar realmente la autoconcepción del Derecho como actividad científica. La misma falacia debe ser evitada en relación con el concepto más general de racionalidad, evitando dar por descontado que la pretensión de corrección del Derecho o su pretensión de autoridad significan eo ipso una justificación de su carácter racional sin necesidad de argumentación adicional epistemológica. Sobre todo si tenemos en cuenta que esta argumentación conduce de manera necesaria, como veremos, a poner en conexión la pretensión de racionalidad del Derecho precisamente con la noción de ciencia.

Sentadas las premisas anteriores, nuestra hipótesis inicial sobre las relaciones entre el estatuto interno y externo de la racionalidad jurídica puede ser reformulada ahora en forma de tesis del modo siguiente. El Derecho no es una ciencia, ni la ciencia jurídica así llamada constituye realmente una disciplina científica, y sin embargo resulta imposible ofrecer una definición de la racionalidad jurídica — aspecto que puede considerarse a su vez definitorio de la institución del Derecho- sin considerar incorporada a ella de algún modo la idea de ciencia (una cierta idea de ciencia). Recíprocamente: cualquier definición del Derecho (sea o no de índole epistemológica) debe dar cuenta de su pretensión de racionalidad, la cual se demuestra fundamentalmente en su vinculación necesaria a la idea de ciencia (estatuto interno), y sin embargo la acepción de ciencia aplicable al Derecho, cuando se considera desde una perspectiva epistemológica general (estatuto externo), resulta muy problemática —en realidad insostenible-, lo que comporta límites sustantivos a esa su pretensión de racionalidad.

Afirmaciones como las anteriores aparentemente incluyen una contradicción, ya que niegan la calificación de ciencia al Derecho y simultáneamente la consideran necesaria. Pero la apariencia se despeja si nos apartamos del planteamiento dicotómico ordinario (el Derecho, ¿es ciencia o no?) para adoptar una visión más global o general

2 Así, p. ej., LARENZ, 1966. En el mismo sentido, MAYER-MALY (1972: p. 13) al afirmar que «la exclusión de la Jurisprudencia del círculo de las ciencias» obedece al propósito de «socavar la autoridad de la dogmática jurídica». 
de la racionalidad del Derecho. En efecto, una de las tres acepciones fundamentales del término «Derecho» hace referencia a algún tipo de racionalidad. Las otras dos se refieren al Derecho como norma y como práctica, es decir, a sus dimensiones normativa e institucional-autoritativa. Puede sostenerse la tesis de que ninguna definición filosófica del Derecho es posible sin poner en conexión de algún modo estas tres acepciones o dimensiones. Y precisamente la pretensión de racionalidad que cabe atribuir al Derecho - y que parte de la conexión entre normas y prácticas, siendo por ello tradicionalmente identificada con una «razón práctica»o «razón normativa»- es la que constituye el fundamento para considerar que la institución jurídica incluye junto a su dimensión justificativa (pretensión de corrección) e institucional (pretensión de autoridad) también una dimensión cognitiva o epistémica, es decir, algún tipo de «cientificidad» o «conocimiento» sui generis, una institucionalización como «técnica», «disciplina» o «ciencia» específica. Esto es lo que lleva a hablar de una «ciencia del Derecho». Ahora bien, ello exige un modelo general epistemológico desde el cual se ofrezca alguna calificación o reconocimiento del estatuto de tal «conocimiento» o «ciencia». Por eso es necesaria la idea de ciencia para dar cuenta de la estructura del Derecho, en tanto se halla vinculada con su misma pretensión de racionalidad. Sin embargo, cuando se establece en concreto, de manera precisa, qué tipo de saber o disciplina es la jurídica, cuando se describe su modo de funcionamiento y se compara con otras ciencias, entonces el resultado de esta comparación determina de modo ineludible que se trata de una ciencia problemática, defectiva, un «caso límite» de cientificidad. Es decir, se llega a la conclusión de que es imposible considerarla como una ciencia estricta o plena, como una racionalidad científica, aun pese a que esta calificación es la que le ha dado configuración propia frente a otras instituciones de carácter práctico o normativo y le ha permitido acuñar una conceptualización epistemológica distintiva. Y esta pretensión de racionalidad, que obliga al Derecho a «cientifizarse» y a mantener una conexión constante con las demás ciencias si quiere seguir llamándose racional, se da en el marco de una vinculación institucional, práctica y normativa, que le impone unos límites y condicionantes decisivos en cuanto que tal pretensión.

No estamos, pues, ante una contradicción, sino más bien ante una dialéctica epistemológica objetiva que refleja una suerte de incompatibilidad o inconmensurabilidad intrínseca que afecta a la racionalidad jurídica en su relación con la racionalidad científica. La mejor manera de comenzar a ilustrar el sentido de esta dialéctica es hacer un recorrido por el periplo histórico de esta relación, lo que podríamos llamar una «historia epistemológica del Derecho».

\section{II}

Las concepciones del pensamiento jurídico han ido evolucionando de forma acompasada, casi coextensiva, con los grandes sistemas históricos de teoría de la ciencia. Las calificaciones del saber jurídico (uno de los más antiguos en occidente) están estrechamente ligadas, desde la filosofía griega, a las concepciones epistemológicas dominantes en cada época y a los modelos de lo que en cada una de ellas se entendía como «ciencia». Y ello tanto en un sentido positivo como crítico o negativo. 
A los efectos que aquí nos importan, cabe distinguir dos grandes periodos históricos: la teoría de la ciencia antigua y medieval y la teoría de la ciencia moderna y contemporánea. En cada uno de ellos (de los que sólo haré un trazo muy general ${ }^{3}$ ) se registra un modelo imperante de ciencia, obtenido de determinadas disciplinas positivas históricamente constituidas que constituyen su referente central. Y, en la medida en que cada uno de esos modelos ha operado como paradigma extensible a todas las disciplinas coetáneas, entre ellas también al Derecho, encontraremos igualmente una versión débil o lata, ampliada, de esos modelos. Identificaremos asimismo cuatro acepciones generales del concepto «ciencia»: ciencia como técnica, como sistema proposicional axiomático, ciencia en sentido moderno y ciencias humanas (véase BuENO, 1995). Es así como la dialéctica antes mencionada puede ser mostrada como una constante histórica. Por una parte, cada teoría de la ciencia histórica suministra una conceptuación epistemológica de la «ciencia jurídica», aportando así una fundamentación positiva para la pretensión de racionalidad del Derecho. Pero, por otra, los mismos modelos han puesto una y otra vez los elementos conceptuales para la crítica de esa idea de ciencia jurídica comparativamente a otras ciencias, lo que determina el surgimiento de una connotación o acepción negativa no sólo para esa idea sino para el estatuto de racionalidad del Derecho en su conjunto. Esto es lo que se ha llamado «el problema de la ciencia jurídica», diagnosticado correctamente por BoBBIO como la existencia secular de una «ausencia de correspondencia entre las nociones de Derecho y ciencia», de manera que éste no se habría visto reconocido como racionalidad científica en ninguno de los modelos o teorías de la ciencia vigentes en cada momento histórico (Bоввіо, 1950: pp. 56, 61 y ss.). Sin embargo, son esos mismos modelos (puesto que no ha habido otros) los que vienen a suministrar las categorías epistemológicas precisas para comprender y dar identidad específica a la estructura (lógica) del Derecho y su racionalidad (y, por tanto, para construir su concepto en términos positivos).

A. Teoría de la ciencia antigua y medieval. Las dos referencias fundamentales de este periodo son el Derecho romano, primer ordenamiento jurídico de rango histórico, y la epistemología de Aristóteles, cuya vigencia general indiscutible se extendió hasta bien entrada la época moderna. Aristóteles introduce la distinción fundamental entre conocimiento teórico (ligado a la verdad) y conocimiento práctico (ligado a la acción) ${ }^{4}$; una distinción crítica, no meramente descriptiva, ya que sólo el primero de estos tipos de conocimiento es considerado en rigor científico: la epistéme, que es un conocimiento universal (derivado de causas y principios universales) y necesario (dotado de una estructura lógica demostrativa o deductiva). El correlato real de este concepto de ciencia es la geometría, que a partir de los Elementos de Euclides fue durante siglos el prototipo de saber científico. El conocimiento práctico en cambio representa la versión ampliada de ciencia, tras constatar que la versión fuerte no resulta aplicable a ciertos dominios que son refractarios a la racionalización científica estricta pese a darse en ellos racionalidad. Estos son los dominios de las técnicas o artes (téchnai) y las prácticas en general (políticas o morales) que, en la medida en que dependen de

\footnotetext{
3 Para un desarrollo pormenorizado me permito reenviar a VEGA, 2000: pp. 35 y ss., 274 y ss., 463 y ss.

${ }^{4}$ Cf. para lo que sigue ARISTÓteles, Analíticos Segundos, I, 2, pp. 71 b9 y ss.; 8, pp. 75b24; 30 y ss. (pp. 316, 333, 385 y ss.); Etica Nicomáquea, VI, 5, pp. 1140a32 y ss. (273).
} 
la acción humana (praxis) son contingentes y variables: es el espacio de la razón práctica, un concepto que llega hasta nuestros días en su contraste con la razón teorética. Aquí será ubicado el Derecho (y también por cierto hasta nuestros días). El propio nombre dado al saber jurídico en Roma - iurisprudentia — proviene de esa ubicación: prudentia es la traducción romana de la phrónesis aristotélica, definida como la virtud rectora del saber práctico estricto, moral y político, vinculado al ejercicio mismo de la acción sobre los otros entendida como aplicación de criterios generales normativos (las virtudes éticas o las leyes políticas) en términos de justicia. Esta sigue siendo la denominación más universal que conocemos del saber jurídico, mantenida hasta el presente (Jurisprudenz, giurisprudenza, jurisprudence). Su significado epistemológico central encierra una acepción de ciencia como «saber hacer», una suerte de racionalidad técnica o práctica intermediaria entre la ética y la política. Desde los inicios de la República, este saber hacer es fundamentalmente el desempeñado por los juristas como clase profesional. El jurista era un iurisconsultus o iurisperitus, un técnico experto en los conocimientos jurídicos al que se acudía en consulta ante cualquier asunto práctico relativo al tráfico negocial privado de la civitas en el que estuviera en juego la aplicación de las leyes, en especial cuando daban lugar a un proceso: el saber del jurista consiste en actuar (cavere, agere y respondere). La actio es el instrumento central de la intervención en el proceso, y el jurista es quien elige la acción apropiada, indica los argumentos de Derecho a desarrollar, etc. ${ }^{5}$ El escenario característico de esta acepción de ciencia es, pues, fundamentalmente el foro (y también la técnica legislativa de los órganos políticos).

Del modelo aristotélico no sólo deriva esta primera acepción de la ciencia jurídica como «arte» o «técnica» práctica peculiar (el ars boni et aequi, tal como lo llama CELSO al principio del Digesto en una fórmula que también evoca la idea aristotélica de equidad, en la que se resume el método de aplicación del Derecho $\left.{ }^{6}\right)$. También se extenderá al saber jurídico una versión debilitada de la acepción fuerte que Aristóteles aplicó a la geometría: la idea de ciencia como «sistema doctrinal de principios». Del conocimiento técnico particularista de los casos y procesos, y de las reglas que los rigen, se pasa a un nivel superior de abstracción y sistematización doctrinal del material jurídico, por efecto de la complejización del ordenamiento, la motivación de los responsa y la aparición de escuelas jurídicas. En este rasgo ha sido localizada muchas veces la diferencia específica del Derecho romano por respecto a los demás ordenamientos antiguos: en su carácter teórico-doctrinal o reflexivo, que incluía una «sistematización» de naturaleza «lógica» o «científica», a base de la elaboración de máximas y reglas abstractas (regulae iuris civilis), definitiones, clasificaciones o genera, ordenaciones expositivas de la materia civil (como las Instituciones de Gayo según el plan personae, res, actiones). El Derecho romano sería así el primer Derecho científico, el que da origen a la «ciencia

5 C. CANNATA, 1989: p. 43; KASER, 1964: p. 21. El jurista juega un papel fundamental en la transformación de la estructura jurídica romana a partir de la introducción del procedimiento formulario en el siglo III a.C., en el cual los propios magistrados y jueces recurrirán a la asistencia técnica del jurisconsulto. Aunque menor, también fue considerable su influencia sobre la legislación (leges y senatusconsulta). A partir del siglo II d.C. toda la aplicación y elaboración del Derecho romano se conformó por mediación de la actividad de los juristas, hasta la sistematización justinianea del siglo vI, el Corpus Iuris Civilis, en la cual se transmitirá al medievo cristiano. En particular, el Digesto, base del saber jurídico en las universidades bajomedievales, no era sino una recopilación de las obras de los juristas romanos de la jurisprudencia clásica (siglo I a.C.-III d.C.).

${ }^{6}$ Cfr. SHINER, 1994: pp. 1257 y ss. 
del Derecho» ${ }^{7}$. De ahí que en los juristas romanos aparezca el nombre de ciencia aplicado al saber jurídico (como la famosa definición de UlPIANO: iurisprudentia est [...] iusti atque iniusti scientia). Pero lo cierto es que, aunque traduce su término al latín, esta scientia no tendrá el sentido de la epistéme aristotélica, esto es, el de una ciencia teórica al estilo de la física o la matemática, sino el de un conocimiento de naturaleza práctica y normativa que cuenta con su propia sistematización escolar. Así, la sistemática de reglas, conceptos y procedimientos lógicos que conforman el cuerpo teórico de la jurisprudencia romana sigue estando subordinada a las técnicas jurídicas (legislativa, jurisdiccional, negocial), es decir, no deja de ser un sistema de «racionalidad práctica» en el sentido de ARISTÓTELES, y no un sistema de proposiciones teoréticas ${ }^{8}$. Se mantiene, pues, el hiato entre prudencia y ciencia en sentido estricto ${ }^{9}$. Una prueba de ello es que esos conceptos teóricos y técnicas lógicas que habrían dado lugar a la constitución de una «ciencia jurídica» son esencialmente los mismos que encontramos en la práctica del Derecho. La presencia de un mayor nivel de abstracción teórica no implica, como sí sucede en las ciencias teóricas genuinas, una distancia respecto de finalidades eminentemente prácticas sino más bien todo lo contrario: la sistematización doctrinal responde en el Derecho al fin de propagar los mismos valores y métodos de la práctica jurídica sólo que ahora en el contexto de la enseñanza académica. Ésta constituye, pues, el escenario propio de esta acepción de ciencia jurídica. De ahí que cuando a partir del siglo XII se retome el estudio del Corpus en las nacientes universidades europeas, la jurisprudencia no fuese considerada una disciplina autónoma, sino una aplicación de la retórica y la dialéctica aristotélicas como instrumentos básicos de la preparación para la práctica forense ${ }^{10}$. Formaba así parte del Trivium, que incluía las «artes liberales» (Gramática, Retórica y Dialéctica) que podríamos considerar continuadoras de las «ciencias prácticas» de Aristóteles (éticas, políticas, jurídicas), mientras que el Quadrivium englobaba a las «ciencias teóricas» (Aritmética, Geometría, Astronomía, Música).

7 KunKel, 1991: p. 109; SCHULZ, 1961: p. 81; La Pira, 1936-7: p. 131. Idéntica valoración hallamos en los grandes juristas alemanes del XIX como SAVIGNY e IHERING.

8 Ya ARISTÓTELES había rechazado en particular que el Derecho pudiese ser objeto de una racionalización lógica o geométrica. La distinción entre los tipos de justicia (distributiva y correctiva) se expresa en términos matemáticos (igualdad aritmética y geométrica), en un intento de establecer criterios objetivos de organización de la polis, pero ello no convierte al discurso de la justicia en un discurso matemático o teorético, sino materia de juicios normativos y valorativos. Cfr. AUBENQUE, 1995: pp. 39 y ss. En general, las ciencias prácticas poseen theoria, pero ésta nunca deja de ser una dimensión interna de las instituciones prácticas respectivas, que no rebasa por ello el ámbito de la razón práctica.

9 Así lo reconoce, p. ej., G. LA PIRA, uno de los autores que más ha insistido en la idea de que los juristas romanos realizaron en el Derecho el modelo de la epistéme aplicado por la geometría de EuCLIDES. Tras comparar el método de ambos, y afirmar que coinciden en el procedimiento de demostración y sistematización a partir de principios (postulados geométricos y normas jurídicas, respectivamente), concluye que los juristas romanos «hicieron pasar la jurisprudencia de la fase empírica a la científica», si bien identificando esta ciencia con un tipo de «técnica» o «ars» y no propiamente con una ciencia estricta [LA PIRA (1935), cita en p. 343]. La misma idea es expresada por muchos otros estudiosos -EsSER, VIEHWEg, SCHUlZ, CoING, KASER - al decir que el sistema jurídico romano fue básicamente un sistema «abierto», inductivo o empírico, casuístico, tópico-problemático, etc., y que en ningún caso tuvo la forma de un sistema «cerrado» de tipo lógico-axiomático, como más tarde, en el racionalismo, podrá decirse también de los códigos de la época moderna.

10 LANGE, 1993: pp. 18 y ss. El método de enseñanza estaba basado en las quaestiones o las disputationes, planteadas como procedimientos de argumentación dialéctica cuyo modelo era el enfrentamiento entre demandante y demandado ante un tribunal (BERMAN, 1977: pp. 907, 927, 935; KANTOROWICZ, 1939: pp. 1-67). Según OTтE (1971: p. 9), «los glosadores nunca conocieron una metodología jurídica propia» diferente de la dialéctica tradicional aristotélica. Sobre las pautas aristotélicas de interpretación y aplicación del Derecho, $c f r$. Retórica, I, 13, pp. 1374aa25 y ss. (285-287); V, pp. $1354 \mathrm{~b} 7$ (165). 
El contraste entre praxis o prudencia y teoría o ciencia está, pues, vigente durante toda la teoría del conocimiento antiguo. Toda forma de conocimiento que exhibiera la forma de un «sistema de proposiciones derivadas de principios», esto es, la estructura axiomático-deductiva de la geometría, fue llamada scientia, desde la Matemática a la Retórica hasta la Teología o la propia Filosofía (como metafísica o «ciencia primera»). Pero ese modelo ideal de cientificidad bajo el que se enjuiciaban todas las disciplinas, proyectándose tendencialmente sobre todas ellas (y este es el rasgo característico del periodo), no era sin embargo satisfecho en realidad por ninguna, exceptuando la propia geometría euclidiana. Ni la física aristotélica o la cartesiana, ni la teología, ni las ciencias del trivium, ni la filosofía llegarán a ser consideradas ciencias en la época moderna. Tampoco la scientia iuris. Como señala KosCHAKER, es más bien una idea de ciencia «en sentido escolástico» $\mathrm{o}$ «doctrinal», que es la acepción de ciencia que correspondía a la jurisprudencia en cuanto disciplina imbricada «en la práctica del Derecho» (KOSCHAKER, 1955: p. 302) y cuyos principios no son universales y necesarios como en las demostraciones geométricas, sino normativos y, por tanto, contingentes y variables, es decir, «dialécticos» (STEPHANITZ, 1970: 35) ${ }^{11}$. La misma dualidad atraviesa todo el iusnaturalismo medieval y su postulado de un Derecho universal invariable de cuyos primeros principios teóricos pudiera deducirse el Derecho positivo (la jurisprudencia práctica). La razón práctica aristotélica, convertida en razón universal por los juristas romanos bajo influjo estoico —naturalis ratio común a todos los hombres generadora del ius gentium ${ }^{12}$-, quedará integrada en la ontoteología creacionista cristiana. La indagación de la naturaleza creada se constituye en procedimiento para alcanzar la comprensión de Dios como supremo creador de las leyes naturales y también supremo legislador moral y jurídicopolítico. Por supuesto, los postulados de esta teología entendida como ciencia suprema que absorbía bajo sí el tratado de la ley y de la justicia servían muy bien para legitimar y «eternizar» el preciso orden político terrenal establecido (las relaciones entre la Iglesia y los Estados surgidos del imperio romano). El iusnaturalismo racionalista que arranca de Grocio y Pufendorf representa en cambio el comienzo de la secularización del punto de vista teológico cuyo origen se sitúa justamente en la aparición del nuevo orden político de la edad moderna y de una nueva concepción mecanicista, no teológicomoral, de la naturaleza y de la «ley natural» (HoBBES, SPINOZA) que está en la base de la tercera acepción histórica de ciencia inauguradora de la epistemología moderna.

B. En la teoría de la ciencia moderna y contemporánea cambia en efecto por completo el panorama del saber. Con la aparición de la física moderna en el periodo que va desde 1600 a 1800 (de GALILEO a NEWTON) entra en crisis la idea «escolástica» de ciencia y tiene lugar la fractura del «bloque ciencia-filosofía» así como la crítica de la metafísica tradicional (KANT). El declive de la ontoteología, los nuevos acontecimientos económicos (la expansión mercantil y geográfica) y políticos (aparición del Estado moderno) determinan el derrumbe de la visión aristotélico-escolástica del mundo. A

11 Una fusión de todos estos conceptos la encontramos en IBN HAZM de Córdoba, quien en el siglo XI clasificó las ciencias en un trivium de «ciencias particulares de cada pueblo», en las que incluye al Derecho junto a la Teología, la Historia y la Filología, y un quadrivium compuesto por las «ciencias comunes a todos los hombres»: Matemática, Medicina, Astronomía y Filosofía ( $c f r$. CRUZ, 1957: I, pp. 249 y ss.).

12 ARISTÓTELES había distinguido entre una ley particular «definida por cada pueblo en relación consigo mismo» y ciertas «leyes comunes» que representan un «acuerdo unánime de todos los pueblos» (Retórica, I, 10, pp. 1368 b6 y ss. [255] y 13 , pp. 1373 b6 y ss. [281]). 
su vez, la consolidación de la «revolución científica» a lo largo de los dos siglos siguientes, XIX y XX, abre camino a la institucionalización de la ciencia experimental contemporánea (la Big Science propia de la sociedad industrial y postindustrial) que instaura una nueva idea de ciencia cuyo modelo estará representado eminentemente a partir de ahora por las ciencias naturales, y cuyo escenario característico es el laboratorio. Esta nueva acepción reclasifica críticamente todos los saberes preexistentes, incorporando el lenguaje matemático, la única ciencia genuina del periodo anterior, de forma que «ciencia» en sentido fuerte o estricto será en adelante exclusivamente la que procede de la Facultad de Ciencias (Biología, Física, Química, Ciencias Exactas, etc.). Se institucionaliza también una nueva filosofía de la ciencia que sustituye a la antigua teoría del conocimiento y centra su reflexión en las nuevas formas de conocimiento: es el positivismo, tanto en su versión clásica decimonónica (COMTE, MiLL) como en su versión contemporánea (el neopositivismo vienés). Generalizando mucho, puede decirse que el positivismo representa la consagración del «monismo metodológico»: sólo existe un método científico, el método de la ciencia físico-natural de base experimental y formulación matemática, basado en procedimientos hipotético-deductivos a partir de la observación empírica (por ejemplo, el «fisicalismo») y conducente a la búsqueda de leyes causales y, en un nivel superior, de teorías explicativas de carácter universal sujetas a contrastación. Sólo aquel conocimiento capaz de asumir este método merecerá ser llamado en rigor «ciencia».

En este periodo, sin embargo, también podemos observar cómo se reproduce un nuevo dualismo en la clasificación de las ciencias. Junto a las ciencias naturales o físico-matemáticas adquiere también relevancia académica desde el Romanticismo un segundo grupo de disciplinas que reclaman una cientificidad autónoma, de signo muy diferente a las primeras. Se trata de las «ciencias humanas» o «sociales», también llamadas en la tradición alemana «ciencias del espíritu» o «de la cultura» (Geistes-, Kulturwissenschaften): la Sociología, la Historia, la Economía, la Filología, la Psicología, la Antropología, etc. La filosofía contemporánea de la ciencia ha girado en buena medida en torno al debate metodológico planteado por las relaciones entre estas dos clases de ciencias y sus metodologías. Un debate que, en cierto sentido, vuelve a reactualizar la vieja oposición aristotélica entre lo teórico y lo práctico, pues la idea subyacente a esta división de la idea de ciencia sigue siendo que sólo aquellas disciplinas que hayan alcanzado una formulación axiomático-formal o matemática de sus leyes, tal que proporcione a éstas una capacidad explicativa universal, un control experimental y una proyección tecnológica, merecen verdaderamente el nombre de ciencia, es decir, de conocimiento teórico. Estos requisitos sólo los cumplirían las ciencias naturales. Las ciencias sociales, en cambio, serían un tipo de conocimiento que versa, no sobre hechos controlables experimentalmente, sino sobre los fenómenos constitutivos de la historia, de la sociedad y de la cultura, y por tanto, sobre contenidos de carácter teleológico, normativo, valorativo (esto es: contenidos prácticos) que no son universalizables sino esencialmente particularistas e irrepetibles (no son «nomotéticos» sino «idiográficos», como dirán RICKERT y WINDELBAND) y cuyo conocimiento específico no puede consistir por ello en la explicación de hechos según leyes causales sino en la interpretación (Deutung) y comprensión (Verstehen) del significado de las formaciones socioculturales en términos de conceptos o teorías que necesariamente han de incluir referencia a razones, fines, normas y valores (como dirán Droysen, Weber o Dilthey). De ahí 
que esta cuarta y última acepción de ciencia (las ciencias humanas) generara su propia epistemología que - también en grandes trazos ${ }^{13}$ — podemos denominar filosofía hermenéutica, representada por los autores de la tradición que va de DiLTHEY a GADAMER o HABERMAS (o incluso al segundo WITTGENSTEIN), y que se caracteriza por sostener en cambio la tesis del «dualismo metodológico», según la cual el método de la ciencia social es distinto y específico al de la investigación científico-natural y no puede ser sustituido por ésta. Todavía dentro de esta teoría de las ciencias sociales se diferencian dos tendencias opuestas: una más positivista que sostiene que la ciencia social debe incluir explicaciones de carácter nomológico (es la posición clásica de WEBER y actualmente, p. ej., la de AlBERT: cf. 1994: pp. 117, 126 y ss.) y otra más interpretativista o hermenéutica que ve en ella no una «ciencia experimental en busca de leyes sino una ciencia interpretativa en busca del significado» (GEERTZ, 1973: p. 5).

También la «ciencia jurídica» experimenta transformaciones sustanciales en esta etapa moderna. Por primera vez se institucionaliza como disciplina académica autónoma y también lo hace el concepto de «ciencia del Derecho» que todavía hoy manejamos. Ello va ligado, como se sabe, al hecho histórico de la positivización y estatalización del Derecho consumada en el siglo XIX, tras el proceso de codificación en que culminó el ideal iusnaturalista de un Derecho racional-universal (así como la recepción de la tradición romanista). Producidas las codificaciones europeas, el «Derecho» deja de identificarse con el ius commune de estirpe romano-canónica para pasar a ser el Derecho del Estado. A su vez, los profundos cambios políticos desencadenados a raíz de las revoluciones burguesas ilustradas implantan progresivamente la idea del Estado de Derecho, que implica la redefinición de los poderes políticos (legislativo, ejecutivo y judicial) como poderes jurídicos. El Derecho positivo se constituye en Derecho nacional monopolizado por el Estado, válido en su territorio y para la población que vive dentro de él. En este escenario surge la dogmática jurídica como ciencia jurídica propia de cada Derecho patrio, vinculada a su transmisión escolar y orientada a la exposición y sistematización del cuerpo objetivo de normas e institutos del sistema jurídico, en una suerte de posición intermedia entre los poderes normativos estatales («cuarto poder», en palabras de LOMBARDI ${ }^{14}$ ). También en términos muy generales de historia de las ideas puede afirmarse que el positivismo jurídico fue la concepción filosófica asociada a este proceso de positivización de las categorías jurídicas y también la responsable de la visión contemporánea del Derecho como ciencia: en concreto su línea alemana (SAVIGNY, IHERING), que acuña la noción de Rechtswissenschaft o «ciencia del Derecho» para designar a la dogmática jurídica como aquella disciplina específicamente enderezada al conocimiento teórico o doctrinal de las normas, conceptos y métodos del Derecho ${ }^{15}$. El método jurídico es fundamentalmente un método dogmático que se agota en la interpretación y reformulación de textos normativos centrales. Esta acepción ha sido incorporada en todas las demás lenguas (science du droit, legal science, scienza del diritto). $\mathrm{Y}$ es la que desde entonces centra los debates filosófico-jurídicos acerca del tipo de cientificidad que realmente envuelve tal metodología dogmática.

13 Una división similar a la trazada en el texto entre positivismo y hermenéutica puede verse en VON WRIGHT, 1987: pp. 21-2, 52 n. 86.

14 LOMBARDI, 1975: p. 498; 1981: p. 176.

15 Cfr. SCHRÖDER, 2001: pp. 191 y ss. 
¿Qué calificaciones epistemológicas subyacen a ese debate? En lo que respecta al Derecho, el modelo de ciencia subyacente no era en realidad nuevo: sólo lo era el modelo que sirve ahora de contrastación crítica (la ciencia moderna). En efecto, el positivismo jurídico decimonónico enfatizaba la dimensión de la dogmática como disciplina teórica, doctrinal (jurisprudencia teórica o «superior», situada por encima de la mera práctica jurídica, legislativa o judicial) y cuyo papel en la configuración del Estado moderno - del Derecho público- fue decisivo ${ }^{16}$. Tal diferenciación funcional entre la práctica y la teoría jurídica, menos marcada en otras tradiciones como la Jurisprudence anglosajona, iba indesligablemente unida a la noción de sistema (central en la escuela de la exégesis, el pandectismo, la jurisprudencia de conceptos, etc.) y esta noción se vinculaba a su vez a la actividad constructiva de la dogmática jurídica. El modelo epistemológico subyacente seguía siendo, pues, el escolástico-aristotélico: ciencia como «sistema de principios» (segunda acepción). Un modelo premoderno que todavía KANT manejaba como criterio de cientificidad ( $\mathrm{y}$ en tal sentido es a menudo citado en la teoría jurídica alemana), cuando estaba asistiendo sin embargo a la aparición de la tercera acepción de ciencia ${ }^{17}$. Y es también esa idea tradicional de ciencia jurídica la que el fiscal VON KIRCHMANN somete a crítica en su famosa conferencia de 1847 Die Wertlosigkeit der Jurisprudenz als Wissenschaft, en donde establece una comparación entre el conocimiento del Derecho por la Jurisprudencia y el de la naturaleza por las ciencias naturales (tercera acepción de ciencia) ${ }^{18}$. Pero será desde el positivismo filosófico donde de un modo mucho más intenso que en KIRCHMANN la problemática de la cientificidad del Derecho llega a su punto álgido: primero, con la crítica comteana de los legistas y su visión «metafísica» de la sociedad, y después, ya en el siglo XX, con el neopositivismo ${ }^{19}$. Por otro lado, además, vista desde el grupo de las ciencias sociales (cuarta acepción), la ciencia jurídica — la antigua jurisprudencia — deja de ser la única disciplina relativa al dominio jurídico, la única «ciencia del Derecho». Desde su mismo origen (y también dentro de la órbita positivista) las demás ciencias humanas hicieron del fenómeno jurídico un objeto de estudio a ser reconstruido bajo esquemas explicativos sociológicos, económicos, históricos, antropológicos... Destaca particularmente

16 Cfr. SCHRÖDER, 1981; MONTANOS, 2004-6.

${ }^{17}$ «Eine jede Lehre, wenn sie ein System, d. i. ein nach Prinzipien geordnetes Ganze der Erkenntnis, sein soll, heißt Wissenschaft» (KANT, 1786: pp. 467). Cfr. SIMON, 1988: pp. 143 y ss.

18 Como se sabe, Von KIRCHMANN argumentaba a partir de la ausencia, en la Jurisprudencia, de un genuino saber objetivo fundado en leyes universales independientes del sujeto (que él sin embargo seguía asociando confusamente a un «Derecho natural»), ausencia que resultaría del carácter contingente y variable del Derecho positivo que se transmite a su propio conocimiento («tres palabras rectificadoras del legislador y bibliotecas enteras se convierten en maculatura»). La relación de la supuesta ciencia con su objeto es más bien de carácter técnico: el jurista sólo opera sobre los defectos de la ley —lagunas, ambigüedades, contradicciones- «como los gusanos sobre la madera podrida» y está condenado a ir «eternamente a la zaga del Derecho»). Cfr. VON KiRCHMANN, 1949 [1847]: pp. 257, 264 y ss., pp. 283-4.

19 Pueden citarse en tal sentido las invectivas de NEURATH contra la ética y la jurisprudencia como «residuos metafísicos» que no se ajustan a la estructura «fisicalista» que debe tener una verdadera disciplina científica dentro de la «ciencia unificada» (NEURATH, 1981: pp. 310 y ss.). O también, dentro del ámbito propiamente filosófico-jurídico, las críticas de A. V. LuNDSTEDT, uno de los pioneros del realismo jurídico escandinavo, quien, en una obra titulada rotundamente La acientificidad de la ciencia jurídica, sostiene que «todo el fundamento sobre el que la ciencia jurídica se ha construido hasta la actualidad consiste en una compacta masa metafísica» y reclama su transformación en una investigación de carácter sociológico o psicológico relativa a hechos sociales empíricos (LundSTEDT, 1932-36: I., pp. 19, 74, 252). En el mismo sentido, Ross, 1961: pp. 89, 117; 1994: 20, 47. 
la sociología jurídica y su crítica del saber doctrinal jurídico (de la dogmática como «ciencia normativa»), que hizo que esa denominación («dogmática») pasara a tener una connotación epistemológicamente despectiva: un estudio de las normas como «dogmas» y no como hechos sociales (lo cual se acompañaba también de una crítica del formalismo jurídico en corrientes como la escuela del Derecho libre, la jurisprudencia sociológica, etc.). Todos los grandes sociólogos — desde DURKHEIM y WeBER hasta LUHMANN, pasando por el marxismo- han elaborado una sociología científica del Derecho en la que la función de descripción, reconstrucción y sistematización de las proposiciones normativas vigentes en un determinado ordenamiento positivo (la función desempeñada por la dogmática) aparece explicada como un dispositivo interno al propio Derecho, que responde a parámetros y factores sociales, antes que una reconstrucción «científica» y objetiva del mismo.

El impacto crítico que sobre la ciencia jurídica —sobre su estatuto externo- tuvo la tercera acepción de ciencia (así como también la cuarta) es, como vemos, notorio y podría decirse que casi definitivo. Ahora bien, también es necesario rendir cuenta de su impacto positivo desde el punto de vista del estatuto interno. Resulta imposible de entender la fisonomía de la racionalidad jurídica dentro de los ordenamientos jurídicos contemporáneos —en su método, en su sistematismo - sin tener presente la influencia positiva, constructiva, que el modelo de las ciencias estrictas ha tenido sobre ella (como la tuvo en su momento el modelo aristotélico al calificar al Derecho como técnica o arte y a la ciencia jurídica como doctrina) ${ }^{20}$. En particular, hay que referirse a una tesis capital del positivismo, cuya relevancia filosófica podremos comprobar en el siguiente epígrafe, como es su reivindicación de un ideal regulativo de objetividad científica rigurosa para la racionalidad jurídica (tanto dogmática como práctica, y en general para la Teoría del Derecho). En esto habría que remontarse al propio KANT y su comprensión de la razón científica (Verstand) como «facultad de las reglas» ${ }^{21}$ que construía las leyes universales de la mecánica newtoniana como juicios sintéticos a prio$r i$. Una idea de regla o ley universal no sólo circunscrita al mundo natural, sino que se postulaba también como aplicable al mundo práctico, en términos de leyes del deber ser o reglas de acción. Se intelectualiza y universaliza así la razón práctica aristotélica, rompiendo con la dualidad secular entre phrónesis y epistéme. Lo que esto significó para la moral lo significó la teoría del deber-ser de KELSEN (via neokantismo) para el Derecho. La kelseniana fue la teoría positivista más importante del siglo Xx, defendiendo la tesis de que la ciencia jurídica es una «ciencia normativa» irreductible a cualquier otra y dedicada al estudio autónomo y objetivo del Derecho, entendido a su vez como dominio autónomo y objetivo delimitado por las reglas objetivas de cada orden jurídico-positivo. Esta idea iba bastante más allá de presentar a la ciencia jurídica como un sistema de proposiciones descriptivas de las reglas del Derecho en la medida en que incorporaba una analogía epistemológica estructural entre normas y leyes naturales que iba a resultar fundamental para entender la racionalidad del Derecho en cuanto basada

${ }^{20}$ Ello puede defenderse tanto en relación con la tradición continental de la teoría general —-formal— del Derecho como en relación con la Jurisprudence anglosajona. Sobre la relación histórica entre positivismo naturalista y jurídico en Alemania, véase TRIPP, 1983: pp. 212 y ss., Sobre la presencia de la analogía con la ciencia natural en la tradición jurídica norteamericana y su influencia en el modelo langdelliano, véase SCHWEBER, 1999.

${ }^{21}$ Kritik der reinen Vernunft, B 171 (p. 131). 
en reglas ideales cuya objetividad quedaba homologada a la de las reglas lógicas o matemáticas pese a tratarse de reglas prácticas orientadas a la decisión subsuntiva de casos particulares. La metodología jurídica moderna desde la Ilustración se funda de hecho sobre esa analogía (la concepción moderna del «legislador racional» y la concepción legalista de la jurisdicción adherida a ella), y lo mismo cabe decir de todas las dicotomías conceptuales de la filosofía jurídica contemporánea (ser-deber, hechos-normas, descriptivo-normativo, naturaleza-sociedad, causalidad-imputación...). El paralelismo metódico sui generis entre racionalidad jurídica y racionalidad científico-natural permite en efecto concebir las normas del Derecho como si fueran «leyes objetivas» de algún tipo: en ambos casos estaríamos ante «reglas» o «hipótesis» de vocación universal y necesitarista cuya aplicación a sus respectivos dominios de hechos (naturales o sociales) permite hablar epistemológicamente de una analogía desde un punto de vista formal o metodológico ${ }^{22}$. Bajo tal premisa han podido ser proyectados sobre la ciencia jurídica todos los diversos modelos metodológicos elaborados por la epistemología contemporánea en relación con la ciencia natural: modelos verificacionistas ${ }^{23}$, falsacionistas $^{24}$, estructuralistas ${ }^{25}$, etc. Otras veces el paradigma lo han ofrecido directamente las ciencias formales entendidas como sistemas axiomáticos deductivos que proporcionan los criterios de racionalidad del Derecho en sus «contextos de justificación» ${ }^{26}$. Como antes se dijo, esta es en general una idea-fuerza de la filosofía positivista de tradición analítica, al menos en cuanto pueda ser identificada con una zona de expansión de la acepción estricta contemporánea de ciencia.

¿Qué valoración global merece esta tradición epistemológica? Habría en mi opinión al menos dos objeciones de fondo que dirigirle. En primer lugar, la noción de racionalidad científica que resulta de la analogía queda excesivamente reducida al plano lingüístico, a la elaboración de un sistema de proposiciones, de un modo sospechosamente similar a lo que sucedía en la idea escolástica de ciencia (segunda acepción). Ese sistema a su vez, se construye sobre las propias proposiciones jurídicas del Derecho, que remitirían a una actividad práctica o técnica en el sentido de la primera acepción. Sin embargo, la sola elaboración de un discurso no convierte en científica a una disciplina y tampoco a la racionalidad práctica del Derecho: se requieren criterios semánticos, materiales y no únicamente sintácticos o lógico-lingüísticos; criterios que establezcan una conexión interna entre ambos —el Derecho y la ciencia que versa sobre él一, ya que el discurso dogmático no es meramente descriptivo, sino constructivo: no es un repetitorium trivial de reglas ni sólo un metalenguaje respecto del lenguaje jurídico. La metáfora de las leyes naturales o lógicas, dicho de otra forma, es solidaria de una epistemología constructivista, mientras que en el trasfondo de la idea de ciencia como descripción lingüística de las normas objetivas del Derecho positivo, asumida

22 Por ejemplo, las proposiciones de la dogmática jurídica pueden ser vistas «como hipótesis en el sentido de la teoría de la ciencia» de tal forma que «las reglas para la discusión de los supuestos dogmáticos se demuestran como perfectamente equiparables con las reglas de la investigación de las disciplinas empíricas» (SAVIGNY, 1976: pp. 9-10). También la metáfora jurídica es un tópico frecuente en la teoría de la ciencia contemporánea. Cfr. VILLA, 1984: pp. 225 y ss.

23 Además de Ross, ya citado, puede mencionarse a FARRELL 1979: p. 171 («exigir que la jurisprudencia se componga de proposiciones verificables es equivalente a exigir que alcance status científico»).

${ }_{24}$ ALBERT, 1993; CANARIS, 1995.

25 SCHLAPP, 1989.

26 Alchourrón/Bulygin, 1971. 
por el positivismo, se esconde una ideología de la neutralidad o Wertfreibeit frente a los valores (materiales y formales) presentes en ellas que resulta epistemológicamente muy poco sostenible, precisamente por ser incompatible con la naturaleza práctica de la racionalidad jurídica en todos sus niveles. La segunda objeción es que, desde la perspectiva semántica, las reglas elaboradas por la dogmática jurídica (al igual que las jurídicas) no son reglas objetivas comparables a las que se establecen en una ciencia en sentido estricto pese a las pretensiones del Sollen. Si bien, como cualquier regla, las jurídicas son reglas pragmáticas, lo son de una manera fundamentalmente distinta a las leyes científicas. Dicho brevemente: son reglas de construcción de sujetos personales (pragmáticamente rectas) y no de objetos impersonales (pragmáticamente oblicuas). Por ello la racionalidad inherente a las reglas del Derecho incorpora de modo constitutivo mecanismos interpretativos de la acción (y, con ello, juicios de valor, de imputación o adscripción, etc.) que no toleran ser reducidos a leyes explicativas o causales de carácter objetivo: aquí son pertinentes en última instancia más los motivos y las razones que las causas (o, si se prefiere, lo que desde HART se conoce como el «punto de vista interno» de las reglas). Es decir: no puede aplicarse una metodología naturalista, sino en todo caso el método de una ciencia social. La analogía, entonces, sólo funciona al nivel pragmático y no al nivel semántico (remitiéndonos en el mejor de los casos a la ciencia como institución social o comunidad científica organizada según reglas, pero sin explicar entonces las diferencias entre ésta y una institución de carácter políticomoral como es el Derecho). Luego volveremos sobre las implicaciones del carácter esencialmente justificativo —en vez de explicativo— de la racionalidad jurídica.

La otra gran línea de la epistemología jurídica contemporánea es la línea hermenéutica, que parte históricamente en cierto modo de críticas como las anteriores. Ya IHERING replicaba a VON KIRCHMANN que la dogmática jurídica — «la teoría del derecho positivo válido en un país»—- sí era en realidad científica siempre que se la considerase incluida dentro de las «ciencias del espíritu» [IHERING, 1992 (1868): pp. 38, 50]. En esta tradición, de nuevo, cada una de las diferentes conceptualizaciones epistemológicas al uso de la cuarta acepción de ciencia han venido igualmente a ser aplicadas al Derecho: la dogmática sería una ciencia cultural-idiográfica ${ }^{27}$, de método normativovalorativo ${ }^{28}$, cuyas pautas de racionalidad son hermenéutico-comprensivas ${ }^{29}$. En esta misma línea podrían ser ubicadas las teorías postpositivistas: la teoría interpretativa del Derecho de Dworkin (por más que carezca de una fundamentación expresamente epistemológica) o las teorías de la argumentación jurídica (PERELMAn, AlEXY, MACCORMick, la concepción pragmática de ATIENZA) y demás teorías de la rehabilitación de la razón práctica. Ciertamente, este parece el lugar adecuado para la dogmática jurídica qua disciplina interpretativa de normas, «ciencia normativa», que a fin de cuentas constituye uno de los ejemplos de racionalidad hermenéutica más antiguo que conocemos. Sin embargo, también hay objeciones que hacer a esta calificación. En primer lugar, el propio concepto de «ciencia social» o «humana» resulta muy problemático, al menos cuando mantenemos un criterio riguroso de cientificidad que siga adoptando como referencia irrenunciable la idea de verdad objetiva de las ciencias naturales y for-

\footnotetext{
27 RADBRUCH, 1959: pp. 158 y ss.

28 KantorowicZ, 1962: pp. 83 y ss., 134; WeBER: pp. 224 y ss., 330 y ss., 536.

29 EsSER, 1972; LARENZ, 1996; KAUFMANN, 1979.
} 
males (BUENO, 1995). Muestra de ello son las polémicas metodológicas de carácter estructural (entre internalismo y externalismo, holismo e individualismo metodológico, historicismo y estructuralismo, enfoques explicativos e interpretativos, etc.) que perennemente se reavivan en estas ciencias reflejando la inestabilidad de sus metodologías a medio camino entre los saberes prácticos ordinarios y las ciencias estrictas. Por otra parte, como vimos, tampoco entre las ciencias humanas tiene asegurado un estatuto pacífico la dogmática jurídica, ya que son las ciencias sociales más desarrolladas y más próximas al modelo de explicación naturalista las que ponen en entredicho su carácter científico. Y justamente por el mismo tipo de razones que hacen inaplicable en ella dicho modelo: por tratarse de una disciplina práctica y hermenéutica orientada a la comprensión de normas que renuncia a todo intento de explicación causal o nomológica (en términos sociológicos, económicos...) de las mismas. Este diagnóstico sólo puede eludirse por la vía de trivializar ad hoc el concepto de ciencia social para homologarlo con la racionalidad hermenéutica misma, haciendo entrar en él a la simple actividad de descripción e interpretación de normas (en cuyo caso habría que considerar científico, junto con el jurista dogmático, al juez o funcionario, al agente moral, al experto en un juego o al participante en cualquier actividad social gobernada por reglas de cierta complejidad como pueda ser, digamos, el protocolo).

Todas estas dificultades planteadas por su comprensión como «ciencia» han llevado a retirar la premisa, considerando que la racionalidad dogmática (y jurídica en general) pertenece en realidad al ámbito del saber técnico-práctico y que no sería una racionalidad propiamente científica ni tendría por qué pretenderlo. Se tratará más bien de una «ingeniería social», una «socio-tecnología» o una técnica social ${ }^{30}$. Tal sería el estatuto que mejor se ajusta a su denominación tradicional de «Jurisprudencia» —la vieja idea aristotélica de iurisprudentia - o disciplina anclada en la «razón práctica». Y en efecto seguramente esta es la perspectiva más apropiada para la calificación epistemológica del Derecho y de la dogmática jurídica como «saber hacer»o técnica social específica. Sin embargo, con ello no desaparece la problemática de la cientificidad, ni en el estatuto interno ni en el externo. Por un lado, sigue siendo necesario explicar en términos epistemológicos las relaciones existentes entre el Derecho (la técnica jurídica) y la dogmática en su dimensión teórica o doctrinal. Por otro, hay que dar cuenta también de la involucración de la racionalidad científica en la práctica jurídica y en la teoría dogmática, y con ello del lugar que a la institución del Derecho le corresponde en una cultura eminentemente científica y racionalista como la contemporánea. Es decir, hay que poder reconstruir lo que hemos llamado su pretensión de racionalidad, que consiste precisamente en la exigencia de una conexión necesaria del Derecho con la racionalidad científica aun cuando no pueda ser considerado él mismo una ciencia. Ello requiere dilucidar adecuadamente las relaciones epistemológicas entre teoría y práctica en el campo jurídico, que son ciertamente complejas. Sobre ello versan las tesis del último epígrafe.

30 Pound, 2002 [1942]; Kelsen, 1941; Albert, 1993; AtienZA, 1986. Es interesante advertir que esta idea procede precisamente del ámbito de la ciencia social. 


\section{III}

1. ${ }^{\text {a) }}$ El Derecho es una categoría constituida en torno a un complejo de instituciones prácticas, hecho que impone la «escala» de su racionalidad.

La calificación de la racionalidad jurídica como un tipo especial de saber «práctico», «técnico» o «jurisprudencial», constante en la tradición epistemológica occidental, responde a que lo que llamamos «Derecho» es una institución compleja cuyo propósito es la imposición social de normas mediante dos funciones básicas desempeñadas por varias subinstituciones interdependientes: la función de formularlas in genere e in abstracto (instituciones legislativas) y la función de aplicarlas in casu (instituciones judicativas, incluyendo aquí las judiciales y administrativas). Tal vez la definición más completa del Derecho en esta perspectiva sea la que nos ofrece R. POUND: «un régimen altamente especializado de control social, conducido en conformidad con un cuerpo de preceptos autoritativos, que son aplicados a través del proceso judicial y administrativo», régimen que representa así la «aplicación ordenada y sistemática de la fuerza en una sociedad políticamente organizada» [2002 (1942): 41ss.]. Ese cuerpo de materiales autoritativos que representa el instrumento interpuesto entre los operadores jurídicos y los actores sociales cuyo comportamiento aquéllos pretenden someter a control no se compone solamente de normas o preceptos (los cuales el mismo Pound clasifica en reglas, principios, concepciones y estándares), sino que también incluye ciertos ideales propios de cada tradición y, sobre todo, implica una técnica que articule ambas cosas y permita conducir el control social así institucionalizado. Sobre esta técnica se sustenta la racionalidad jurídica, como conjunto de métodos y procedimientos de producción, desarrollo, interpretación y aplicación de los materiales normativos en cuestión con vistas a la toma de decisiones (legislativas, judiciales, administrativas) mediante las que se pretende resolver los conflictos sociales y dirigir racionalmente la acción de los individuos en función de ciertos propósitos o valores político-morales. En la medida en que el Derecho lleva a cabo tal control diferido y generalizado del comportamiento de los individuos a través del aparato del Estado, en él juega un papel nuclear la idea de autoridad, que entonces aparece específicamente conectada a la de racionalidad y no sólo a las ideas genéricas de dominación, poder, coacción, etc. Ello entraña no ya un sistema de control del comportamiento (uno más entre otros) sino un sistema de control de las prácticas sociales públicamente justificadas en el ámbito político y moral. En este sentido el Derecho opera una racionalización del poder político y de la moralidad por la mediación de una tal técnica autoritativa orientada a la planificación, argumentación y justificación de las decisiones en función de textos e instrumentos normativos centrales.

\section{2. ${ }^{\text {a) }}$ Todo Derecho evolucionado desarrolla internamente una sistemática doctrinal} $o$ «ciencia jurídica».

El Derecho es la normatividad social más abstracta, tecnificada y abarcadora, por cuanto i) se construye en un segundo orden respecto de todas las demás normas, ii) se vincula al Estado y iii) se positiviza de una manera altamente formalizada a través de un lenguaje específico cuyos interlocutores primarios son fundamentalmente los pro- 
pios actores jurídicos. Estos rasgos la convierten en una técnica normativa característicamente doctrinal, reflexiva o «teórica», es decir, cuyo manejo exige el desarrollo de teorías específicas capaces de generar concepciones generales justificativas (un law in books, en términos de Pound [1910]). Teorías, por un lado, de carácter sectorial relativas a los contenidos de las instituciones jurídicas propias de cada campo — de sus reglas, principios, valores fundamentadores-y que precisamente reciben el nombre tradicional de «doctrinas» (p. ej., la doctrina del error, la buena fe o el dolo eventual). Por otro lado, concepciones teóricas o ideológicas fundamentales de carácter más comprensivo que proporcionan al jurista una representación global de su función (p. ej., una teoría del Estado de Derecho, de la constitución o de los derechos humanos). Podemos llamar a ambas, siguiendo a VieHWEg (1991: pp. 35, 44 y ss.), «teorías materiales» ${ }^{31}$. Pero el Derecho exige también teorías específicamente técnicas o formales: aquellas que conforman la metodología jurídica en sentido estricto al ordenar las pautas de producción, interpretación y aplicación de las normas del Derecho en términos de principios formales tales como los de coherencia (de valores), consistencia (de reglas), completud y decidibilidad (de las resoluciones singulares), etc., principios que abren paso a la visión del Derecho como un sistema. Estas son las pautas definitorias de la racionalidad jurídica, del método jurídico, hasta el punto de que WEBER pudo identificar en ellas el «tipo ideal» de Derecho «racional-formal» característico de la tradición occidental ${ }^{32}$. Son por ello pautas y principios en buena parte ellos mismos codificados «metalingüísticamente» mediante normas positivas, haciendo así patente la naturaleza metódica del Derecho. Es la regulación de las propias funciones de producción y aplicación de las normas lo que demuestra que el Derecho es una técnica basada en la justificación «cerrada» o autosubsistente de las decisiones a partir de normas previas y que en ello radica su autonomía frente a otras disciplinas y otros métodos.

La fuente principal de las teorizaciones formales y materiales antes mencionadas es la dogmática jurídica (incluyendo aquí la iusfilosofía como «alta dogmática»). Ésta se da en continuidad con la técnica jurídica: si la técnica tiene teorías incorporadas a su proceso dinámico, la dogmática consiste en reconstruir este proceso desde esas teorías, es decir, desde el punto de vista de su «cierre» o sistema continuado y de sus concepciones justificativas envolventes. Supone así un nuevo mecanismo de racionalización que genera una institución jurídica más, tan imprescindible para la conformación del Derecho como las otras dos, legislativa y aplicativa, siendo en realidad un mecanismo exigido por la complejización progresiva e independencia relativa de ambas en los sistemas jurídicos modernos, esto es, por razones prácticas relativas a la recursividad de las decisiones de la técnica jurídica y la armonización de las representaciones normativas que las justifican. Es también el vehículo a través del que discurre, en las facultades jurídicas, la formación especializada y el aprendizaje profesional de los juristas, así como la transferencia social y estabilización de las interpretaciones jurídicamente acep-

31 HABERMAS se refiere aproximadamente a lo mismo cuando habla de los «paradigmas de Derecho», aquellas «imágenes implícitas de la propia sociedad que dan una perspectiva a la práctica de la producción legislativa y de la aplicación del Derecho» (2005: p. 473).

32 Tal racionalidad tiene que ver con la generalización (elaboración de reglas a partir de casos) y la sistematización (construcción de un orden superior a partir de principios) que vuelve a la técnica decisoria jurídica previsible y calculable dados ciertos parámetros valorativos materiales. WEBER, 1993: pp. 509 y ss. 
tadas a lo largo del tiempo ${ }^{33}$. Dado que en este proceso los conceptos y teorías de la dogmática, una vez establecidos, pasan a incorporarse a la propia estructura normativa del Derecho, al margen de ella no cabe hablar del «orden jurídico» de una sociedad política dada. Y esta es la razón que hace necesario que un Derecho suficientemente diferenciado y desarrollado en el medio social y político desarrolle internamente una disciplina doctrinal específica, llámese ésta «dogmática jurídica» o de cualquier otra forma, a la que hay que suponer, en algún sentido, como disciplina científica en relación con su objeto, las normas y prácticas del Derecho (cabría recordar aquí el concepto savigniano de «Derecho científico») ${ }^{34}$. La dogmática es, pues, junto con la procedimentalización y sistematización de las normas con las que se dirige la técnica jurídica, la principal manifestación institucional de la pretensión de racionalidad interna del Derecho. Es ésta la que lo conecta, no ya con la «pretensión de corrección» o fundamentabilidad vinculada a las justificaciones formales y materiales de sus normas, excluyente de todo decisionismo espontáneo, sino con un discurso constitutivo de una precisa racionalidad científica (que por supuesto incluye, como hemos visto, concepciones ideológicas, filosóficas, morales...) cultivada por «autoridades teóricas» y no sólo prácticas.

3. $\left.{ }^{a}\right)$ Ahora bien: ni siquiera adoptando el canon mínimo —o más laxo- de cientifcidad, la «ciencia jurídica» puede ser reconocida realmente como racionalidad científica.

Cuestión distinta es cómo se relaciona la dogmática jurídica, en ese su papel interno racionalizador respecto de la técnica jurídica, con otras racionalidades científicas (estatuto externo). Hemos comprobado cómo de la historia de la epistemología se desprende el dato recurrente e incontestable de que el saber jurídico-dogmático no es clasificable ni dentro de las ciencias en sentido estricto (naturales y formales) ni dentro de las ciencias en sentido débil (sociales); a lo sumo quedaría incluido en aquellas disciplinas más periféricas dentro de estas últimas cuya calificación como científicas resulta, sin embargo, de una generalización vacua del concepto de «ciencia» a toda actividad normativa. Respecto a la epistemología antigua y medieval, como vimos, son muy ciertas las palabras de KOSCHAKER: «El lenguaje románico usual es en este punto muy claro, pues evita el empleo de la palabra "ciencia" y habla solamente de teoría del Derecho y de doctrina, a las cuales contrapone la jurisprudencia, subsumiendo en esta palabra la práctica del Derecho y el Derecho elaborado por la judicatura». Y este diag-

33 Ello se corresponde con dos de las funciones principales que ALEXY y LUHMANN señalan como características de la dogmática jurídica: i) de acuerdo con su dimensión «empírico-descriptiva» (que en realidad es técnico-normativa), la función informativa y de transmisión y aprendizaje del Derecho vigente; ii) de acuerdo con su dimensión «analítico-lógica», la función heurística de estabilización, sistematización, integración, flexibilización y refinamiento del material textual-normativo. Cfr. ALEXY, 1989: pp. 255 y ss.; LuHMANN, 1983: pp. 27 y ss. Luego volveremos sobre una tercera e importantísima función.

${ }^{34}$ Por supuesto, los productos del discurso teórico sobre el Derecho —en este plano dogmático — son muy variados: van desde la simple reproducción reflexiva de los textos normativos, pasando por el «sombreado» mediante glosa o comentario puntual de los mismos y de sus aplicaciones recaídas en decisiones oficiales, hasta la construcción doctrinal en sentido estricto a base de teorías comprensivas que abarquen una institución concreta (p. ej., una teoría del delito imprudente o de la letra de cambio) o todo un campo jurídico (la teoría general del negocio jurídico, del acto administrativo, etc.). A estas teorías, que constituyen el exponente máximo de la labor dogmática (de su consideración como racionalidad científica), al operar como dispositivo de racionalización y renovación de la estructura normativa del Derecho, me refiero en el texto como «materiales» (las «formales» tendrían más bien que ver con la teoría general del Derecho como summa de las «partes generales» de cada rama). 
nóstico se mantiene en la teoría de la ciencia moderna y contemporánea: de ahí que el mismo autor concluya — refiriéndose a críticas como las de LUNDSTEDT- que «el negar a la teoría del Derecho, especialmente a la dogmática jurídica el carácter de ciencia en la acepción moderna de esta palabra, más que censura implica una tautología» ${ }^{35}$.

La pretensión de racionalidad del Derecho, que explica el surgimiento de la dogmática, no sirve entonces por sí sola para justificarla como disciplina científica. Esto implica considerar infundado, desde un punto de vista epistemológico, que la simple diferenciación funcional entre Derecho y dogmática —entre el discurso jurídico y el discurso dogmático- sea base suficiente para considerar a este último como científico, bastando para ello aducir que ninguna otra disciplina se ocupa del análisis y reconstrucción de las normas, métodos y conceptos del Derecho positivo. La relativa autonomía institucional del discurso dogmático frente al Derecho y su carácter conceptualmente específico no proporcionan en sí mismas un criterio de cientificidad. Ajena a criterios externos generalizables (un concepto general de ciencia o de racionalidad), tal visión de la dogmática jurídica (y en esto vienen a coincidir tanto las visiones hermenéuticas como las analíticas de la «ciencia jurídica») en realidad se limita a «blindar», apoyada en los criterios internos, una valoración positiva acerca de su carácter científico, evaporando el problema filosófico-epistemológico subyacente (o reduciéndolo a una mera cuestión nominal, gremial o ideológica). Y el problema epistemológico de fondo es que, siendo así que la dogmática proporciona esquemas de racionalidad necesarios para el Derecho como sistema decisorio, queda por demostrar si el Derecho mismo es racional: es decir, si lo es de un modo que vaya más allá del discurso dogmático. A este interrogante hay que dar una respuesta positiva, como luego veremos, pero ésta no puede fundarse en que la dogmática, ni el Derecho, sea una ciencia. Pues, como hemos visto hasta aquí, son las mismas razones que hacen necesario el discurso dogmático las que impiden de manera igualmente necesaria que sea una ciencia cuando se mantiene un criterio mínimamente riguroso de calificación (haciendo aflorar así el problema epistemológico tradicional). El asunto es, pues, estructural: el Derecho no sólo no es una racionalidad científica, sino que no puede serlo. Y esas razones están estrechamente emparentadas con la proximidad de escala que la dogmática mantiene con el Derecho. En particular, con la relación de continuidad que la vincula con el progreso de la práctica jurídica. Esto nos lleva a la tesis siguiente.

\section{4. ${ }^{a}$ La dogmática jurídica no es tampoco una técnica ni una tecnología.}

Si la dogmática jurídica no es una ciencia, de ello se sigue que su relación con el Derecho no puede ser la de una técnica ni la de una tecnología. El discurso dogmático no sólo constituye un discurso interpretativo al versar sobre las normas jurídicas y elaborar una representación abstracta y sistemática de éstas, sino que es también un discurso justificativo o comprometido prácticamente con dichas normas y los valores implicados en ellas, es decir, entretejido con las propias prácticas jurídicas en curso (un compromiso que es el fin objetivo de la institución, con independencia de las preferencias de cada individuo en particular). Así, por ejemplo, la dogmática penal (la «teoría general del delito») está comprometida con la práctica del Derecho penal y los valores que ésta promueve (los «bienes jurídicos»), frente a contravalores reales, de

35 KosChaKer, 1955: pp. 302 y 476 respectivamente. 
manera que sus desarrollos teóricos se integran tanto en la legislación como en la jurisprudencia penales y podría decirse que, junto con éstas, constituye una dimensión más de la «política criminal» en su conjunto en la perspectiva de su cumplimiento social justificado. Esta implantación práctica se pone de manifiesto en lo que diferentes autores llaman la dimensión «legislativa», «práctico-normativa», «heurística» del discurso dogmático, o sea, su capacidad para elaborar «nuevas normas jurídicas» y completar el ordenamiento bien a través de las normas establecidas, bien mediante el desarrollo de normas no establecidas ${ }^{36}$. El discurso dogmático elabora así nuevas propuestas y contrapropuestas para la práctica jurídica en la previsión y decisión de casos y problemas tanto en la dirección lege ferenda como sententia ferenda. Como antes dijimos, esta es la función técnica, instrumental y adaptativa de la doctrina jurídica imprescindible para la racionalización y progreso de cualquier ordenamiento complejo, por la cual se fija el marco de lo «jurídicamente posible» y se persigue el cambio y el perfeccionamiento de la práctica jurídica en la dirección del ius condendum o del «mejor Derecho posible» ${ }^{37}$.

Sin embargo, epistemológicamente hablando, esta no puede ser llamada en rigor una dimensión «técnica». Es más bien, en todo caso, la práctica jurídica de base la que constituye una técnica de control social. La institucionalización de la racionalidad dogmática responde a exigencias funcionales internas de ésta relacionadas con la estabilización y generalización de sus procesos reglados de decisión normativa (LUHMANN, 1983: pp. 30; 1987: pp. 354 y ss.). Por lo tanto, no es la dogmática la que dirige a la práctica jurídica, sino que en realidad es dirigida por ella. Aunque la propuesta de nuevas normas y justificaciones está formulada en la perspectiva de su aplicabilidad futura por las instituciones legislativas y judiciales, no tiene el carácter determinista — de aplicación de reglas objetivas - que distingue a una técnica o una tecnología: la dogmática no funciona en el Derecho como la ingeniería (en cuanto aplicación de las ciencias físicas) o la medicina (en cuanto aplicación de las ciencias biológicas). Más bien su relación con la institución legislativa o la judicial es del mismo tipo que la que éstas mantienen entre sí (esto es, una relación entre discursos prácticos coextensos de contenido político-moral). Pues la dogmática está siempre a expensas de que sus sugerencias críticas y planteamientos normativos sean de hecho aceptados e incorporados por los decisores jurídicos, que son los únicos que efectivamente llevan adelante la técnica jurídica imprimiéndole un rumbo u otro. Si una teoría dogmática tiene la mayor perfección y corrección conceptual, pero no es secundada (o deja de serlo) por los

36 Cfr., entre otros, CANARIS, 1995: p. 30; ALEXY, 1989: pp. 241 y ss.; SAMPAIO, 1978: pp. 89, 122 y ss.; HARENBURG, 1986: pp. 184 y ss. Como apunta NiNO, «si las teorías dogmáticas sólo sirvieran para explicar normas positivas consistirían meramente en una versión simplificada de éstas»; pero su característica principal consiste precisamente «en su capacidad para presentar las reglas creadas por la dogmática jurídica como derivadas del Derecho positivo» (1974: pp. 79, 81).

37 Es lo que KOSCHAKER llama «Derecho de juristas» (Juristenrecht), concepto que generaliza a partir del Derecho romano (1955: pp. 247 y ss., 300 y ss.) y que reactualiza el «Derecho científico» de SAVIGNY. Como ejemplos clásicos podemos mencionar justamente las monografías de SAVIGNY e IHERING acerca, respectivamente, de la posesión y la culpa in contrabendo, rápidamente incorporadas al Derecho positivo alemán. En la misma línea va el «Derecho jurisprudencial» de LOMBARDI como «cuarto poder» normativo. Es preciso hacer notar, sin embargo, que los periodos de «Derecho legislado» también se caracterizan por intensas elaboraciones previas de carácter doctrinal que sirven de base a las obras codificadoras (otros dos ejemplos clásicos: las dogmáticas civilistas de DOMAT y POTHIER respecto del Code napoleónico y el usus modernus pandectarum previo al BGB alemán). 
legisladores al emprender sus reformas o por los jueces al aplicar las leyes, dejará de hacerse operativa como teoría en el Derecho. De modo que las relaciones entre la teoría y la práctica están aquí invertidas: es la práctica la que en última instancia selecciona qué doctrina seguir, confirmando, refutando o adaptando libremente aquellas que le son propuestas desde la dogmática, en función de sus propios intereses y opciones político-morales. Las que hemos llamado teorías materiales decantadas en la práctica del Derecho positivo, siempre imbricadas en sus teorías formales, tienen la primacía sobre las teorías dogmáticas y no a la inversa. La ciencia, la «teoría», no guía objetivamente la práctica como sucede en las ciencias aplicadas, sino que es guiada (y desbordada continuamente) por ella. Las autoridades teóricas o dogmáticas del Derecho muestran una dependencia esencial respecto de sus autoridades prácticas. Ello es la consecuencia epistemológica del hecho de que la metodología ejercitada por la dogmática no supone en absoluto una «distancia teórica» frente a los conceptos operativos en la técnica del Derecho. Estos conceptos llegan tan lejos en su significado y alcance como lo hagan las operaciones decisorias autónomas de legisladores y jueces al emplearlos e interpretarlos en clave justificativa, y cualquier reconceptualización teórica de los mismos en sede dogmática debe plegarse a este hecho. Y por eso cabe sostener que son esas operaciones técnicas (político-morales, en realidad) las que forman el «núcleo generador» de la categoría jurídica. Aquí reside la verdad profunda del aserto de VON KIRCHMANN sobre las «tres palabras rectificadoras del legislador» (aserto que en su simple superficie es falso, dado que existe un acervo doctrinal invariante).

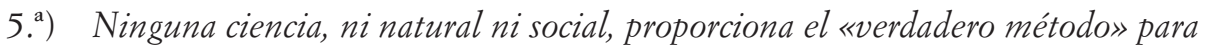
convertir a la racionalidad jurídica en una racionalidad científica.

¿Significa lo anterior que la auténtica clave explicativa del Derecho, la verdadera «ciencia jurídica», debe buscarse en las ciencias sobre el Derecho ya que no en la ciencia del Derecho? Es decir, en aquellas ciencias externas que representan el modelo fuerte de cientificidad vigente desde la época moderna (ciencias naturales y formales), o aquellas que, encarnando un modelo débil, ofrecen sin embargo puntos de vista explicativos sobre el fenómeno jurídico (que, entre otras cosas, revelan a la dogmática como un dispositivo funcional suyo). La respuesta ha de ser negativa, y obedece de nuevo a razones sustantivas de objeto y método.

Es indudable la aplicabilidad de enfoques naturalistas en la investigación de los fundamentos de las normas e instituciones jurídicas en tanto éstas regulan aspectos del comportamiento humano y están por ello afectadas por la acción de causas de orden natural, p. ej., sociobiológico (GRUTER, 1993). Como también pueden ser aplicadas las estructuras lógicas al análisis del Derecho como sistema proposicional normativo. Este tipo de reconstrucciones, con arreglo a su propia metodología, revisten un nivel de objetividad máximo (el de una racionalidad científica estricta) y demuestran además que existen contextos externos al marco jurídico en los cuales cabe hallar una explicación profunda de sus normas y prácticas (el «punto de vista externo» es, pues, muy pertinente para construir «el concepto del Derecho»). Sin embargo, hay al menos tres razones que conducen a descartar que por esta vía pudiera llegarse a construir algo así como una ciencia natural (o formal) del Derecho. La primera es que se trata de la proyección parcial de otras ciencias ya constituidas a fragmentos que se inscriben en el campo específico del Derecho, lo que es muy diferente de la construcción de una 
ciencia cerrada sobre este campo en su integridad a base de metodologías naturalistas (o lógico-matemáticas). La segunda razón es que, por ello, son conceptualizaciones de carácter genérico: no dicen nada específico del Derecho, sino que se aplican a éste de igual modo que a otros fenómenos no jurídicos, mostrándolo bajo la acción de unas mismas leyes o teorías universales. Y, en tercer lugar, son explicaciones cuya objetividad y verdad indiscutibles dejan sin embargo infradeterminado el plano de la racionalidad práctica, en el que se mantienen las normas y valores constitutivos del Derecho. Al resolverse en factores impersonales, independientes del observador, las explicaciones científico-objetivas abandonan ontológicamente la trama de elementos configuradores de la praxis humana (juicios de valor, inferencias prácticas, intenciones, etc.) y con ello dejan también de proporcionar en sí mismas fundamentos decisorios de carácter práctico, es decir, razones. Por ejemplo, las leyes de la genética molecular constituyen sin duda un marco objetivo determinante de las reglas del parentesco y de la filiación tal como aparecen codificadas en el Derecho civil. Pero a partir de aquellas leyes no pueden ser directamente obtenidas estas reglas. El concepto jurídico de paternidad no se agota en el concepto biológico, sino que lo modula (y muchas veces lo rectifica) en un diferente nivel de racionalidad en el que lo relevantes son las redes de relaciones prácticas entre los individuos y su configuración normativa en términos de derechos y obligaciones. En este nivel las causas biológicas no son por sí solas pertinentes, sino sólo en el marco de los balances de razones (en función de valores, intereses, expectativas, derechos, etc., de los individuos) que realiza el legislador cuando formula sus reglas o el juez cuando las aplica ${ }^{38}$. Tampoco las relaciones temporales que el Derecho toma en cuenta (al regular instituciones tales como los plazos, la usucapión, la reincidencia, etc.) se corresponde con el tiempo científico de la física (medido a través de leyes objetivas astronómicas o subatómicas) sino con un tiempo vivencial, el tiempo «práctico-empírico» (BRETONE, 1999: p. 41), de manera que nada tiene que decir la ciencia natural (que aporta sin embargo la más rigurosa racionalización de las magnitudes físico-temporales) cuando se trata del tiempo normativo del Derecho, cuya racionalidad se da a una escala práctica (días, meses, años, décadas) medida en función de operaciones biográficas de los individuos, ritos sociales de paso, etc. (sería impracticable medir los plazos jurídicos civiles o administrativos en — digamos— nanosegundos) ${ }^{39}$.

38 Piénsese en el modo como el Derecho tiene presente, pero transformando su significado, las verdades biológicas al establecer las presunciones de filiación (art. $116 \mathrm{Cc}$ ). O simplemente las desconoce, como en la prohibición de investigar la paternidad biológica en casos de adopción: aquí operan razones derivadas de balances de intereses y derechos (constitucionales, civiles, etc.) de cada uno de los vértices del «triángulo adoptivo» (padres biológicos, padres adoptivos, sujeto adoptado). Sólo dentro de este marco valorativo pueden hacerse jugar los argumentos naturalistas. Por ejemplo, OAKLEY (1985) considera justificado un derecho a investigar la propia paternidad biológica del adoptado argumentando la existencia de un patrón innato de conducta adaptativamente seleccionado que inclina a todo sujeto a conocer sus ancestros genealógicos y su procedencia genética y cuyo fundamento evolutivo estaría en las mismas causas que explican la selección reproductiva de la exogamia o la evitación del incesto (OAKLEY, 1985). Pero argumentos de este tipo, aun teniendo fundamento objetivo y racionalista, pierden su carácter «determinista» al tener que ingresar en ese marco justificativo, en competencia con razones normativas, y ser transformados en juicios de valor, algo que sólo sucede mediante el ejercicio de razonamientos prácticos.

${ }^{39}$ Con todo, la incorporación de la escala temporal marcada por el reloj en las relaciones jurídico-normativas es la incorporación de la máquina racionalista por excelencia de la revolución científica — «El reloj, no la máquina de vapor, es la máquina-clave de la moderna edad industrial», MUMFORD, 1987: pp. 31 y ss., 56 y ss., 151—, que ha impuesto la estandarización de las relaciones sociales, administrativas y económicas en la sociedad industrial moderna (frente a las sociedades agrarias, regidas sólo por el calendario). 
Mutatis mutandis, lo mismo puede decirse de las ciencias sociales y su pretensión de haber alcanzado un conocimiento verdaderamente científico del Derecho (a diferencia de la dogmática del jurista), de forma que solamente serían «ciencias jurídicas» el análisis económico del Derecho, la sociología jurídica, la antropología jurídica, etc. Lo cierto es que estas ciencias parten necesariamente (a diferencia de las ciencias en sentido estricto) de una aproximación interpretativa a los fenómenos socioculturales que constituyen su objeto (el Derecho en este caso), razón por la cual carecen también de un grado de objetividad comparable. Como señala VON WRIGHT (1987: pp. 158-9), las ciencias sociales no serían en su mayor parte sino sistemas de interpretaciones. En la medida en que incluyan además explicaciones objetivas de índole nomológica se reproducirán los problemas anteriormente señalados del carácter inespecífico y sobredeterminado de tales explicaciones por respecto a la racionalidad jurídica. Por ejemplo, un análisis histórico o económico del surgimiento del Derecho mercantil tendría que referirse al desarrollo de la economía capitalista centrada en torno a la empresa o la gran empresa; explicaría así qué factores causales determinaron el surgimiento de la sociedad anónima, como sociedad con responsabilidad limitada y partición de su capital en acciones, respecto de sociedades mercantiles anteriores (p. ej.: las vastas posibilidades de ganancia sin riesgo que comportaba, el valor mobiliario del capital en forma de acciones, etc.; cf. GALGANO, 1990: pp. 79 y ss.). Pero esta explicación de la funcionalidad económica del concepto jurídico de sociedad anónima, siendo verdadera, no sería por sí sola un fundamento suficiente para reconstruir en su totalidad, pongamos por caso, la legislación de sociedades anónimas de un determinado ordenamiento jurídico, ni menos aún para extraer juicios concluyentes específicos sobre cómo interpretar o aplicar el contenido de sus preceptos particulares en una cierta situación en términos de derechos y obligaciones. De ahí podrán obtenerse muchas interpretaciones singulares a efectos prácticos, pero éstas no serán ya científico-objetivas, sino valorativas (y lo normal es que ambas cosas se entremezclen ilegítimamente en las ciencias sociales: de ahí la pertinencia del postulado metódico de la Wertfreibeit weberiana). Esta situación se plantea invariablemente a propósito de las reconstrucciones científico-sociales del Derecho que incluyen metodologías de base matemática, tales como las técnicas estadísticas en sociología, el aparato formal de la teoría de la decisión racional y la teoría de juegos en el análisis económico, etc. La explicación que la ciencia social ha hecho del Derecho, con su crítica del «punto de vista interno-normativo» del jurista, no ha supuesto algo así como la eliminación definitiva del discurso dogmático-jurídico ni su sustitución por una «tecnología social» de base exclusivamente sociológica o económica que sea independiente de los juicios valorativos y normativos de naturaleza político-moral que caracterizan la actividad de un juez (convertido en supuesto científico social o «ingeniero social») o de un legislador (convertido en agente regulador en el sentido de la theory of economic regulation; véase CODERCH, 2004). Como señaló KELSEN en general contra el sociologismo: «Del mismo modo que, mientras exista una religión, deberá haber una teología dogmática que no puede reemplazarse por ninguna psicología o sociología de la religión, así también, mientras haya un Derecho, existirá una doctrina normativa» (KELSEN, 1960: p. 26).

Por consiguiente, una cosa es que el Derecho (o algunos fragmentos suyos) obedezca a pautas o funcionalidades que pueden tener su explicación profunda en otros 
contextos extrajurídicos y otra que la racionalidad jurídica pueda ser reducida in integrum a esas racionalidades extrajurídicas, viendo en él algo así como una «superestructura» que simplemente reflejara las relaciones objetivas determinadas en éstas. Esto supone incurrir en la falacia naturalista (algo en lo que, paradójicamente, coinciden el iusnaturalismo tradicional y el cientificismo moderno). Sucede más bien que existe una suerte de correlación inversa entre el grado de cientificidad (de objetividad) de las metodologías de tales categorías externas y su grado de conmensurabilidad con el método jurídico. La práctica interpretativa y decisoria que caracteriza a éste se mantiene resistentemente a un nivel autónomo de racionalidad que permanece irreductible a cualquier explicación científico-objetiva, y esta es la razón de fondo de la imposibilidad estructural de que la racionalidad jurídica pueda convertirse en una racionalidad científica. Ahora bien, de esta afirmación no puede inferirse en modo alguno la tesis de la insularidad epistemológica del Derecho. Eso sería tanto como destruir la pretensión de racionalidad del Derecho en cuanto institución de la razón práctica. Con esto llegamos a la última y más importante tesis.

6. ${ }^{a)}$ La racionalidad práctica jurídica, sin embargo, no puede construirse a espaldas de la racionalidad científica sino que está necesariamente conectada con ésta en virtud de la pretensión de racionalidad del Derecho.

Al igual que sucede con otras cuestiones filosóficas suscitadas por el Derecho (como el problema de sus orígenes, su estructura y función, su fundamentación axiológica), la cuestión de la racionalidad, no tolera un tratamiento exclusivamente internalista. Por el contrario, exige transitar desde el interior de la categoría jurídica a otras categorías externas ${ }^{40}$. Las ciencias modernas no sólo han significado una transformación del concepto filosófico (epistemológico) del Derecho, especialmente en el panorama de las ciencias sociales, donde ha visto desaparecer su posición tradicional de dominio o centralidad. Han supuesto también una transformación profunda de su propia fisonomía como racionalidad práctica. No, como hemos visto, en el sentido de haberse logrado su «cientifización» ni tampoco su conversión en una posible tecnología (ya sabemos que el concepto de «ingeniería social» es sólo una metáfora). Pero sí en cuanto a la aparición en su entorno de disciplinas elaboradas a base de complejos de conocimientos de diferentes ciencias sociales, incluso de técnicas y procedimientos de las ciencias naturales y lógico-matemáticas, que, pese a la inconmensurabilidad de escala entre sus respectivos conceptos y teorías, han podido constituirse como «ciencias auxiliares» de la técnica jurídica (un caso ejemplar es la criminología o las «ciencias forenses» respecto del Derecho penal). Que sean «instrumentales» del Derecho es un indicio más de que se trata de conocimientos que operan como una prolongación de la propia técnica normativa jurídica, con los límites que ello comporta, y no a la inversa, como verdaderas tecnologías científicas aplicadas al Derecho. Pero lo que interesa resaltar es cómo este hecho pone de manifiesto que lo que hemos llamado la pretensión de racionalidad del Derecho —que lo vincula internamente a una racionalidad «formal», sistemática y dogmática, basada en la justificación de reglas y valores-, establece también una conexión necesaria con la racionalidad científica externa y sus criterios de verdad, en vez de conducir a incomunicarlas entre sí.

40 Esta es también la razón de que el «concepto del Derecho», precisamente por ser «fronterizo» a diferentes racionalidades intra y extrajurídicas, sólo pueda ser construido desde una filosofía del Derecho. 
Esa conexión puede ser identificada en las tres instituciones jurídicas: por un lado, la legislación y la jurisdicción (que conforman la técnica jurídica) y, por otro, la dogmática jurídica. Me centraré, sin embargo, principalmente en la institución judicial. La moderna teoría de la legislación ha puesto de manifiesto que en la deliberación y argumentación legislativas confluyen racionalidades extrajurídicas de muy heterogénea naturaleza, desde científicas y técnicas hasta morales y políticas, y poca justificación requiere la vinculación entre el legislador, como figura práctica edictora de normas, y la noción de racionalidad ${ }^{41}$. En realidad, la entera «técnica jurídica» está basada en esta noción, si entendemos tal técnica organizada por el conjunto de pautas normativas que desde la instancia legislativa se diseñan para regular las prácticas aplicativas e interpretativas de las autoridades que integran el aparato jurisdiccional y administrativo como parte de su función motivadora. En la medida en que la regulación de las operaciones prácticas de los ciudadanos destinatarios del Derecho (mediante reglas que «atrincheran» determinados valores materiales) incluye también la regulación de las operaciones decisorias de quienes deben aplicar esas normas a las situaciones prácticas singulares dadas en la vida social, el diseño institucional de la técnica jurídica está esencialmente comprometido con la idea de fundamentabilidad racional que subyace a la necesidad de motivación, esto es, de justificación y argumentación de las interpretaciones y decisiones adoptadas ${ }^{42}$. Al margen de esta idea carece de sentido la propia racionalidad de dictar y seguir reglas prácticas: tanto desde el punto de vista de las autoridades jurídicas (p. ej., la coherencia pragmática implicada en el «legislador racional» exento de contradicciones, la congruencia valorativa entre precedentes o interpretaciones pretéritas, la revisión y rectificación de las decisiones por tribunales superiores, la derrotabilidad, etc.) como desde el punto de vista de sus destinatarios (p. ej., la publicidad, predecibilidad, no retroactividad, etc., como condiciones racionales de la imputabilidad y garantes de la autonomía) (LAPORTA, 2007: pp. 83 y ss., 127 y ss., 193 y ss.).

Pero es en la institución jurisdiccional donde la pretensión de racionalidad aparece comprometida, no ya con la fundamentabilidad en general en razón de reglas, sino específicamente con la noción de verdad. El dato capital al respecto es la presencia en el proceso judicial (y, por extensión, en el administrativo) de una fase probatoria como parte del procedimiento de toma de decisiones. Es en efecto esencial al proceso, en cuanto técnica para la resolución de conflictos en aplicación de las reglas jurídicas, el establecer o acreditar los hechos tipificados por éstas a fin de aplicar sobre ellos las consecuencias o efectos que esas mismas reglas prevén. La interferencia inmediata del Derecho en la vida social que tiene lugar a través de los jueces (el legislador actuaría en cambio mediatamente), determinando el significado y efectos que sus reglas suponen respecto de las situaciones prácticas particulares, exige también fijar y reconstruir los hechos en litigio y pronunciarse sobre su verdad. Y ello como una exigencia interna de la propia racionalidad práctica que rige el Derecho (y que justifica en realidad la razón de ser misma de las instituciones aplicativas): la imposición argumentada y justificada

${ }^{41}$ Cfr. ATIENZA, 1997 y 2004: pp. 102 y ss.

42 ALEXY, 1989: p. 208. No es extraño, por ello, que en la teoría contemporánea del Derecho la idea de regla haya llegado a homologarse con la de razón (razones para actuar, razones subyacentes a las formulaciones normativas) así como la de «autoridad normativa» con la de racionalidad. Véase un enfoque crítico en BOUVIER, 2004. 
de las decisiones adoptadas con base en las reglas jurídicas. El valor de la justicia depende aquí del valor de verdad ${ }^{43}$.

La articulación de la reglamentación procesal en términos de un denso conjunto de reglas de factura epistemológica o cognitiva (como las presunciones o las diferentes reglas relativas a la selección, presentación y valoración de los elementos probatorios) manifiesta la codificación práctica que la racionalidad jurídica hace de la idea de verdad. La institución judicial está diseñada legislativamente en términos que pretenden ser garantes de la objetividad (fiabilidad, pertinencia, congruencia y suficiencia de las pruebas), la imparcialidad (examen por un tercero independiente de los intereses de las partes) y la eliminación del error en las decisiones (exclusión de pruebas epistemológicamente espurias como el testimonio de referencia, control intersubjetivo de la actividad probatoria) ${ }^{44}$. En todos los códigos procesales aparece el mandato al juez de aplicar las reglas de la lógica, la razón, la «sana crítica», etc., y asimismo se impone modernamente el principio general de la libre apreciación de la prueba (es decir, su vinculación central a los solos criterios epistemológicos). Todos estos son rasgos racionalistas homologables en principio, desde el punto de vista metódico, a los que rigen cualquier empresa de investigación científica: «un buen juez no sólo debe conocer las normas sobre admisibilidad de las pruebas o sobre el procedimiento probatorio, sino también los métodos de conocimiento de otras ciencias, dado que su labor es muy semejante en lo esencial a la de científicos e historiadores» ${ }^{45}$. Por ello la ciencia es para el Derecho «un modelo óptimo de conocimiento al que también la comprobación procesal de los hechos debería aproximarse» ${ }^{46}$. Y así, el testimonio pericial científico entra efectivamente en juego en el proceso judicial a partir de la eclosión de las ciencias modernas, tanto en su tercera como cuarta acepción, evidenciando con ello la transformación de la técnica jurídica a que antes nos referíamos ${ }^{47}$.

43 Como señala TARuffo (2006: p. 136), «la verdad de la determinación de los hechos es una condición necesaria, si bien, obviamente, no suficiente para la justicia de la decisión». En palabras de HAACK (2008b: p. 986), «substantial justice requires factual truth». Sobre la verdad como objetivo último de la institución probatoria, FERRAJOLI, 1995: pp. 551 y ss.; FERRER, 2005: pp. 31, 71 y ss. Es clara la vinculación de este punto con el derecho de defensa o el requisito de un proceso con todas las garantías como exigencia del Estado de Derecho (derecho a la prueba, a no sufrir consecuencias jurídicas de hechos no probados). La presunción de inocencia, por ejemplo, es un derecho de calado epistemológico: sólo puede ser destruida si se demuestra la culpabilidad en virtud de pruebas suficientes (sobre el carácter veritativo de las presunciones jurídicas como reglas inferenciales inductivas, $c f r$. PEÑA/Ausín, 2001; la presunción de inocencia sería en realidad, según estos autores, una no-presunción de culpabilidad).

44 Cfr. GASCÓN, 1999: pp. 115, 125 y ss.; FERRER, 2005: pp. 40 y ss. El hecho de que la institución probatoria esté diseñada desde el punto de vista del legislador (diríamos, en tercera persona) permite deslindar sus fines epistémicos objetivos de los que puedan tener las partes y el propio juzgador.

45 GonzÁlez Lagier, 2006: pp. 130. Cfr. TARUFFO, 2002: pp. 330 y ss.; FerRajoli, 1995: pp. 141 y ss.

46 TARUFFO, 2006: pp. 138-9.

47 JaSANOFF, 1995: pp. 42 y ss.; GOLAN, 2004: caps. 2 y 6; MONAHAN/WALKER, 2009: pp. 104 y ss.; 396 y ss. En EEUU la incorporación de perspectivas científico-sociales tuvo lugar bajo la influencia de la sociological jurisprudence realista. Sobre el giro histórico en dirección racionalista vinculado a la Ilustración, cfr. GASCÓN, 1999: pp. 27 y ss.; FERRAJOLI, 1995: pp. 33 y ss.; sobre la cientifización de la «tecnología del poder» penal y de los procedimientos de prueba a partir de entonces, FOUCAULT, 2005: pp. 29 y ss., 45 y ss. La propia concepción moderna y contemporánea de la «prueba» jurídica (evidence) va ligada desde BENTHAM o WIGMORE a la comparación del Derecho con los procedimientos de indagación y demostración de las ciencias tanto naturales como sociales conformando una tradición efectivamente racionalista (TWINING, 2006: pp. 35 y ss.). Pero esta comparación no hubiera sido posible si la técnica jurídica procesal misma no respondiera a una pretensión de verdad ligada a la razón práctica que ya preexistía a la ciencia moderna y en cuya procedimentalización por los juristas bajomedievales algunos autores (como BERMAN, 1977: pp. 907, 927 y ss.) ven el germen de la 
Este hecho tiene también una inmediata repercusión en la «desdogmatización» del saber jurídico, de la «ciencia jurídica» como tercera institución del Derecho. El «dogmatismo» que caracteriza a ésta no puede ser homologado ya con el de otros discursos vinculados a textos centrales revestidos de autoridad institucional, como pueda ser el de la teología. Si bien cabe decir que en ambos casos se trata del ejercicio de «interpretaciones normativas», orientadas a una comprensión no «cognitiva» sino con fines prácticos - la obtención de una decisión jurídica, asegurar una cierta creencia religiosa- (BETTI, 1990: II, pp. 789 y ss.), se impone una diferencia fundamental. El corte epistemológico que la dogmática teológica establece con respecto a la racionalidad científica es abrupto y total, en cuanto va orientada al blindaje y aseguramiento de creencias explícitamente «praeterracionales» (y de ahí el carácter constitutivo del conflicto ciencia-religión a partir de la época moderna), mientras que eso no sucede ya en el Derecho. Como vimos, el carácter «dogmático» de las doctrinas jurídicas deriva de que su tratamiento de las normas del Derecho no persigue una explicación científico-objetiva de las mismas en términos naturalistas o socioculturales, y ello porque su horizonte interpretativo está decisivamente «cerrado» por la técnica decisoria que está a la base de esas normas, fundamentalmente las instituciones aplicativas judiciales y administrativas. En ellas se trata de decidir sobre el significado práctico de esas normas - qué puede hacerse, qué está permitido y prohibido con arreglo a lo establecido por el legislador-y la teoría dogmática no pretende tanto un «conocimiento científico» de tales normas cuanto influir sobre aquella toma de decisiones. Así, se sitúa epistemológicamente al mismo nivel teórico que las propias normas y sus concepciones envolventes de carácter justificativo. Esto le impide ser una ciencia, pero no una disciplina racionalista y crítica: sólo que la crítica se hace a este preciso nivel normativo y justificativo, desempeñando con ello una importante función racionalizadora del Derecho. Sin embargo, por ello mismo, en la medida en que la propia técnica decisoria jurídica necesite incorporar en sus procesos de justificación material (i.e., con arreglo a los contenidos de cada norma) razones, premisas o elementos de juicio de carácter científico-objetivo, también será necesario incorporarlos en el discurso de la dogmática jurídica. Y eso es exactamente lo que reclama la pretensión de verdad que rige la institución jurisdiccional en su fase probatoria, de forma además creciente en una sociedad ella misma hipertecnificada en donde las tecnociencias han modificado las relaciones sociales y las condiciones de vida de los individuos (p. ej., en el ámbito biomédico) impactando en las propias estructuras jurídicas del «Estado regulador». De manera que, en el Derecho, a diferencia de la teología (y esto desbarata la comparación kelseniana más arriba citada), la vinculación fundamental a un sistema de decisiones institucionales públicas sí hace relevantes los fundamentos de verdad científica que quepa recabar para la fundamentación de las decisiones, es más: los convierte en parte esencial de su justificación. El Derecho no puede establecer un corte absoluto con la racionalidad científica; por el contrario: incorporarla es una exigencia de su propia pretensión de racionalidad práctica. Ahora bien, esto no significa que haya desaparecido la inconmensurabilidad entre el discurso científico, en sus diversas gamas, y el discurso jurídico de la que hemos hablado. De hecho, puede que

investigación científico-experimental en occidente (exposición de puntos de vista distintos, debate y conclusión mediante una decisión objetiva por parte de una instancia neutral que toma partido en virtud de las evidencias presentadas). 
la institución de la prueba sea el contexto más apropiado para examinar de cerca los términos de esa inconmensurabilidad entre, por así expresarlo, el laboratorio y el foro, entre las convenciones científicas y las convenciones jurídicas (SANDERS, 2009). Ya que es aquí donde se revela con mayor claridad hasta dónde puede llegar la pretensión de racionalidad del Derecho incluso cuando invoca en su auxilio las verdades o esquemas de racionalidad de las ciencias más rigurosas. $\mathrm{O}$, si se prefiere, hasta qué punto puede ser realmente satisfecha esa pretensión en cuanto que tal.

El punto central al respecto, como hemos ido viendo hasta aquí, tiene que ver con el hecho de ser un escenario de racionalidad práctica aquel en el que pretenden hacerse valer tales verdades objetivas procedentes de metodologías científico-teóricas. Esto es, un escenario en el que se trata: i) de la reconstrucción de la acción humana (y su constelación), ii) desde otra acción, la emprendida técnicamente, con fines decisorios o de control social, en el marco de la institución aplicativa, y ii) de una reconstrucción gobernada por reglas específicas. De aquí derivan las resistencias o límites que la «epistemología de la razón práctica» impone a cualquier intento de trasladar a su ámbito esquemas racionales o metódicos elaborados a otras escalas conceptuales que no versan inmediatamente sobre la acción (ciencias estrictas) o pretenden someterla de algún modo a teorizaciones y explicaciones de índole nomológica (ciencias sociales). Límites, por tanto, que aunque suelen llamarse «institucionales» o «normativos», son en última instancia de naturaleza epistemológica o vinculados a las metodologías respectivas. Pues también las ciencias son instituciones normativas y regladas ${ }^{48}$, sólo que en ellas la metodología de investigación no está orientada a la toma de decisiones respecto de terceros sujetos, es decir, no son instituciones de carácter político-moral. En cambio, las reglas epistémicas procesales están no sólo cerradamente formalizadas sino diseñadas como un instrumento para la puesta en práctica de las reglas sustantivas del Derecho, expresivas de otros valores igualmente sustantivos cuya consecución es el fin institucional primario. La determinación de la verdad se halla, pues, a su vez supeditada a la justicia. Como consecuencia de ello el régimen de la prueba (establecido por el legislador y que obliga al juez) puede comportar restricciones en la averiguación de la verdad de los hechos o la directa exclusión de la validez jurídica de ciertos resultados probatorios que, epistemológicamente legítimos fuera del foro, se estima que lesionan esos valores y por eso quedan probibidos dentro de él ${ }^{49}$. Quedan así a veces (no siempre y no totalmente) en suspenso las reglas epistémicas generales al quedar legitimada la posibilidad de que el juez se vea obligado a no considerar probados hechos verdaderos, a declarar probados hechos que no hay fundamento para tener por tales o incluso a declarar probados hechos falsos (es decir, que el Derecho ofrezca una reconstrucción falsa de la realidad). Surge entonces inevitablemente la diferenciación entre la verdad material y la verdad formal o procedimental, esto es, la verdad determinada en el marco contextual del proceso en función de las pruebas admitidas por los filtros normati-

48 Sobre las reglas del ethos científico (universalismo, objetivismo, desinterés en la búsqueda de la verdad, etc.) y los sistemas de sanciones con que se protegen, $c f r$. MERTON, 1985. Véase también SANDERS, 2009: pp. 64 y ss.

${ }_{49}$ Son, por ejemplo, las reglas que prohíben las pruebas ilícitamente obtenidas en violación de garantías o derechos constitucionales fundamentales de los justiciables (inviolabilidad del domicilio, secreto de las comunicaciones, derecho a no declarar, babeas corpus, integridad física, etc.) o las pruebas que se considera que atentan contra otros valores jurídicos (la seguridad del Estado, el parentesco, el secreto profesional, etc.). 
vos mencionados. El hecho, sin embargo, de que estas reglas «contra-epistemológicas» (GASCÓN, 1999: p. 122y ss.) deban estar justificadas en virtud de criterios garantistas o morales (y no sean por tanto arbitrarias, ya que extra forum no se justificarían) significa que no queda completamente anulada la pretensión racionalista de verdad que anima el proceso (tal como sostienen ciertas interpretaciones de esa distinción en dirección justamente irracionalista) ${ }^{50}$. Sólo significa que esas reglas reflejan cómo en el Derecho la verdad no es un valor aislado sino un valor práctico cuyo alcance, como pasa con todos, debe ser ponderado racionalmente con el de otros parámetros valorativos, lo que en ocasiones tasadas lo vuelve relativamente disvalioso (o valiosa a la desviación de la verdad) ${ }^{51}$.

Si tales reglas son contempladas desde el marco práctico en que se ponen en juego, la técnica del proceso, se revelan las limitaciones que ésta, en cuanto técnica precisamente decisoria orientada a resolver conflictos sociales, impone sobre las pretensiones de objetividad de la institución probatoria. Dicha finalidad decisoria por sí misma puede entrar en incompatibilidad con el objetivo de determinación de la verdad (cf. DAMAŠKA, 1986: pp. 97 y ss.; SANDERS, 2009: pp. 68 y ss., 74 y ss.). No ya por el hecho de que la estructura estratégica o «adversarial» (y también «teatral», narrativa, retórica) del juicio implica un control de las partes sobre las pruebas alegadas (pudiendo en consecuencia desarrollar estrategias de ocultación, manipulación, connivencia, etc.) en función del derecho de defensa (cuyos fundamentos dialógicos-racionalistas son por otro lado indiscutibles, en la medida en que presuponen las reglas de la argumentación pública como única vía para reconstruir los hechos en litigio) ${ }^{52}$. Sino sobre todo por los obstáculos que suponen las exigencias internas de una técnica puntual o particularista de decisión caso a caso como la jurídica que sin embargo tiene que generalizar normativamente sus razones en términos de coherencia justificativa y engranaje pragmático entre instituciones. Así, son tajantes las limitaciones temporales impuestas por la prescripción, los plazos, etc., la configuración «cerrada» (TARUFFO, 1992: pp. 317 y ss.) de la instrucción y el propio juicio (quod non est in actis non est in mundo) y la necesidad de que éste arroje una respuesta correcta (prohibición del non liquet) culminando con una última decisión que se impondrá por vía autoritativa como cierre definitivo del asunto por parte del Derecho (res iudicata, irrevisabilidad de las cuestiones de hecho salvo casos excepcionales de aparición de nuevas pruebas) ${ }^{53}$.

Pero es sobre todo si consideramos el objeto de esta técnica como se llega al fondo de todos sus problemas epistémicos o metodológicos. En efecto, ¿de qué clase de «hechos» hablamos y qué clase de objetividad es posible cuando se trata de una técnica de decisión sobre acciones bumanas? Los hechos en cuestión consisten en (o se con-

50 Cf. críticamente al respecto, FERRER, 2005: pp. 61 y ss.; TARUFFO, pp. 24 y ss.; GONZÁLEZ LAGIER, 2003 b: pp. 47 y ss. Estas concepciones de corte irracionalista (persuasivo, narrativo, etc.) deben explicar por qué siguen necesitando el concepto de verdad (formal, jurídica, judicial, forense, etc.).

51 Cabe recordar aquella definición irónica que BENTHAM aplicó a la Jurisprudencia: «el arte de ignorar metódicamente lo que es conocido por el mundo entero» [1823 (1959): I, p. 243]. Ya Hegel decía, refiriéndose a las ficciones del Derecho romano y la racionalidad pragmática a que obedecían, que «es más bien la inconsecuencia de los juristas y pretores romanos lo que hay que apreciar como su mayor virtud» [1821: $\mathbb{\$} 3$ (p. 65)].

52 Sobre las presunciones como reflejo de la configuración dialéctico-argumentativa del juicio proceso en términos de reglas de distribución de las cargas probatorias, $c f r$. AGUILÓ, 2006.

53 El carácter técnico-institucional del proceso judicial determina que la controversia no se cierre por «resolución» (epistémica) sino por «terminación» (autoritativa) (SANDERS, 2009: pp. 70 y ss.). 
figuran esencialmente en torno a operaciones de individuos acontecidas en el pasado que tienen que ser reconstruidas en el proceso (son facta probanda) y tienen que serlo en tal precisa condición de hechos idiográficos o singularidades prácticas irrepetibles. Es, pues, una fenomenología pragmática — de «hechos institucionales»— cuyo nivel de reconstrucción objetiva sólo puede ser interpretativo, en razón de aspectos como los siguientes: i) la identificación de esos hechos está en función de sistemas de propósitos, percepciones, intereses, representaciones mentales, tablas de valores, etc., que han de ser imputados a los agentes implicados por el juzgador; ii) los criterios de relevancia al respecto vienen establecidos por las propias reglas materiales jurídicas (por los tipos de acción y demás elementos de ésta contemplados en sus predicados fácticos) ${ }^{54}$; iii) el escenario contradictorio del proceso presenta al juez los hechos ya normativamente preinterpretados con arreglo a versiones antagónicas; iv) los elementos de prueba que tienen que ser recabados y examinados para determinar la verdad de esos hechos en litigio no son a su vez sino signos a interpretar: su valor probatorio consiste justamente en el significado que poseen para organizar coherentemente el «teatro de operaciones» en discusión; tales elementos de prueba son ellos mismos indicios de carácter práctico (rastros operatorios, documentos, testimonios, etc.) o bien - y aquí entra en juego la prueba científica- reconstrucciones de componentes genéricos, dimensiones contextuales o resultantes objetivos de las operaciones en cuestión que implican la aplicación tecnológica de conocimientos teóricos (estadísticos, bioquímicos, físicos, etc.); iv) la reconstrucción judicial de los hechos es a su vez episódica o singular, como consecuencia de la propia naturaleza idiográfica de la técnica jurídica de decisión en la que los hechos en cuestión sólo son investigados en el proceso por una única vez («efecto Rashomon» producido por el principio de inmediación ${ }^{55}$ ); v) los criterios de valoración de la prueba, tanto los legales como las «máximas de experiencia» usadas en las inferencias judiciales, son de carácter doxástico, prudencial o dialéctico en el sentido de Aristóteles, esto es, se basan en el «conocimiento práctico ordinario» o de «sentido común» (el «criterio humano») sobre lo que «suele suceder en la mayoría de los casos», la «opinión del hombre medio», de «los más sabios», etc. (están destinados, pues, a formar parte de razonamientos prácticos); y, finalmente, vi) la prueba o reconstrucción judicial de los hechos forma parte de una técnica social cuya finalidad primordial es la imputación de los efectos prácticos o consecuencias jurídicas tipificadas en las reglas jurídicas, es decir, influir causalmente sobre las acciones enjuiciadas (y el conjunto social) promoviendo los valores subyacentes a dichas reglas; el Derecho es una técnica de construcción normativa de individuos prácticos como personas dentro de un marco justificativo de valoraciones de carácter moral y político ${ }^{56}$.

54 Las normas del Derecho son el criterio que dirige en todo momento la selección, individualizan y construcción del «caso». Éste es, por tanto, el resultado de una construcción retrospectiva operada desde la técnica jurídica más bien que una determinación objetiva de «lo realmente sucedido». Por otra parte, las descripciones factuales de las normas típicamente están hechas en términos del lenguaje ordinario, con la consiguiente carga valorativa, vaguedad, etc. Cfr. Taruffo, 2002: pp. 96 y ss., 109, 128 y ss., 228 y ss.; GONZÁLEZ LAGIER, 2003a: pp. 23 y ss.

55 Cfr. CARDín, 1988.

56 Consecuencia de ello es que los estándares de prueba poseen una conformación normativa en la que entran en juego no sólo razones epistemológicas acerca de las condiciones en que una «hipótesis del caso» es verdadera (en virtud de criterios de confirmación, refutación, coherencia, etc., sobre la base de los elementos de juicio probatorios) sino también razones político-morales acerca de cuándo puede tenerse por suficientemente probada a la hora de adscribir responsabilidades y atribuir las consecuencias jurídicas correspondientes, 
En vista de todo ello se explican las dificultades epistemológicas objetivas de traducibilidad, dentro de las inferencias probatorias judiciales, entre las metodologías interpretativas que exige la determinación de los hechos pertinentes para el Derecho y las metodologías características de las pruebas científicas que implican la construcción de patrones nomológicos objetivos. Es el problema de hasta qué punto la verdad práctica necesaria para la imposición de las normas jurídicas puede ser determinada desde la verdad científica. La primera orienta la investigación judicial y marca su nivel epistemológico de racionalidad (dado que son esas normas las que establecen los nexos causales relevantes a partir de los verbos de acción contenidos en sus supuestos prácticos de hecho), y en ella se trata de un proceso de reconstrucción de fines e intenciones que deben individualizarse en torno a sujetos. La segunda, en cambio, no maneja ya esquemas de racionalidad de carácter teleológico relativos a las relaciones entre acciones humanas, sino relativos exclusivamente a estados de cosas objetivos susceptibles de cuantificación, universalización y demostración. El problema, en suma, es si la conceptualización científica posible de la acción humana, en sus componentes objetivos genéricos o universales, suministra elementos de juicio cualificados para el tipo de individualizaciones y adscripciones en torno a acciones y sujetos singulares que caracteriza a la racionalidad práctica de cuya acreditación se trata en el juicio. Y aquí reaparece de nuevo la escisión epistemológica entre ciencias naturales y sociales, pues mientras que es muy discutible que tales elementos de juicio puedan ser obtenidos de forma suficiente e incluso relevante mediante la aplicación de métodos cuantitativos de tipo probabilístico-estadístico, pese a todo su aparato matemático bayesiano ${ }^{57}$, o la aplicación de métodos psicológicos empíricos (p. ej. para la prueba de la intencionalidad) ${ }^{58}$, las técnicas metodológicas de tipo naturalista (p. ej., genéticas) permiten reconstrucciones de carácter demostrativo conducentes a inferencias unívocas en relación con la identificación de acciones y agentes individuales. Pero incluso en este último caso no son per se concluyentes: es preciso dar el paso que lleva desde tales demostraciones a su valoración normativamente relevante in casu. Y este paso ya no es él mismo científicoobjetivo, sino un paso que sólo puede ser realizado mediante la interpretación de un individuo —el juez- que actúa como peritus peritorum ejercitando finalmente juicios de valor ético-políticos mediante razonamientos prácticos.

En efecto, las inferencias probatorias son razonamientos prácticos en tercera persona mediante los que se reconstruye la acción ex post actu en función de razones o intenciones del agente (en el sentido de VON WRIGHT (1987: pp. 49, 142), quien se remite al silogismo práctico aristotélico) y por eso son inferencias interpretativas. Pero esas razones atribuidas al actor están a su vez interpretadas desde las razones y valoraciones

razones que de acuerdo con las distintas formas de organización de la técnica jurídica (en el campo civil o en el penal) entrañan valoraciones sobre la repercusión de los posibles errores probatorios, su diferente o igual distribución entre las partes («más vale absolver a cien culpables que condenar a un inocente»), el coste económico implicado, etc. Cfr. BAYÓN, 2008: pp. 5 y ss.; FERRER, 2005: p. 69.

57 Cfr. TRIBE, 1971: pp. 1349 y ss.; Allen, 1991-92: pp. 383 y ss., 393 y ss. Véase la excelente discusión crítica en TARUFFO, 2002: pp. 215 y ss.

58 Cfr. PAREDES, 2001: pp. 73 y ss., 88 y ss. La intencionalidad relevante a efectos jurídicos implica identificaciones normativas y no meramente empíricas: el juzgador reconstruye singularizadamente la conducta de los individuos a la luz de reglas jurídicas a fin de poder interpretarla como acción (dolosa, culpable, etc.) y tal cosa no puede ser realizada desde los conceptos psicológicos (ni de la neuropsicología ni de la psicología cognitiva). 
subyacentes a las reglas jurídicas, como razones valiosas o disvaliosas, en términos de «hipótesis de calificación»), interpretación de la que depende la asignación inmediata de consecuencias jurídicas. Y este es un razonamiento en primera persona ejercitado por el juzgador tomando partido valorativamente en uno u otro sentido. Aquel primer razonamiento tiene lugar, por consiguiente, en el marco de éste (y sólo así es posible). Ninguna otra cosa significa que estemos hablando de una «técnica»: también responde a la tesis aristotélica de que el silogismo práctico tiene su inicio en una situación particular, la racionaliza bajo ciertas premisas normativas y vuelve a ella modificándola por el intermedio de una acción o decisión como conclusión de quien está llevando a cabo el razonamiento. Aquí está la causa última de que sean difícilmente separables entre sí las cuestiones de prueba y de calificación, la questio facti y la quaesti iuris. Lo que no implica en absoluto desvincular a la primera de la idea de verdad, considerándola agotada en una actividad puramente valorativa o decisionista, sino más bien entender ésta como una verdad práctica en la que la determinación de los hechos - y una determinación tan objetiva como pueda serlo la que arroja una prueba de ADN con un 99,9 por 100 de fiabilidad - depende necesariamente del ejercicio de juicios de valor (dicho de otra forma: implica entender la relevancia de la prueba como un concepto valorativo). La verdad relevante que puede prevalecer epistemológicamente en el proceso judicial está, en suma, condicionada por la ontología pragmática del Derecho como técnica social, que reconoce al juez la discrecionalidad (la intime conviction) y la autoridad para llevar a cabo tal género de decisiones y juicios de valor en aplicación de sus reglas.

La indeterminación introducida por esta «variable abierta» valorativa explica también que haya podido darse el fenómeno contemporáneo del uso incorrecto, y el abuso sin más, de la evidencia científica en juicio (la llamada «ciencia basura») como consecuencia de la admisión irrestricta de elementos de prueba (incluyendo los pseudocientíficos) cuya validez el juez o el jurado no están en condiciones de valorar adecuadamente, de su mera manipulación a fines ideológicos o religiosos (en las disputas sobre creacionismo-evolucionismo, aborto, transfusiones de sangre, etc.) o de los sesgos derivados del simple interés de parte ${ }^{59}$. Este hecho no puede eclipsar sin embargo el uso correcto generalizado de pruebas científicas que, contra cualquier escepticismo, refuerza una visión del Derecho como empresa epistemológicamente racional cuyos criterios de corrección no pueden ser sólo internalistas o normativos sino también externos ${ }^{60}$. Pero sí pone de relieve hasta qué punto su pretensión de racionalidad está en dependencia de la «filosofía de la ciencia» practicada por los tribunales ${ }^{61}$ y en general por las concepciones teóricas metodológicas internas a la técnica jurídica. La exigencia de que éstas incorporen doctrinas filosóficamente fundadas sobre bases críticas de cualquier género de irracionalismo jurídico — que aquí significa dogmatismo y subjetivismo incontrolados - y capaces de promover estándares racionalistas de prueba en la instancia legislativa y «técnicas de motivación» adecuadas de la cuestión de hecho en la judicial se revela por ello como una exigencia epistemológica que —en una técnica

59 Cfr. Huber, 1991; Faigman, 1999; HaACK, 2008a.

${ }^{60}$ Un ejemplo claro son los estudios críticos de la psicología empírica sobre la percepción y la memoria en relación con la fiabilidad y validez del testimonio. Véase WoOCHER, 1977.

61 Véase HAACK, 2005 a propósito de los criterios (popperianos y hempelianos) adoptados por el Tribunal Supremo de EEUU —en el conocido caso Daubert (1993) — en relación con la fiabilidad del conocimiento científico aceptable en juicio. 
pública de decisión como el Derecho- es al mismo tiempo moral y política. Solamente así la justificación racional de los juicios de valor inherentes a la aplicación de sus reglas, que es una pretensión epistémica asumida por la institución, podrá alcanzar también —y pese a todo— su mayor efectividad práctica.

\section{BIBLIOGRAFÍA}

Aguiló, J., 2006: «Presunciones, verdad y normas procesales», Isegoría, 35: pp. 9-31.

AlBERT, H., 1993: Rechtswissenschaft als Realwissenschaft. Das Recht als soziale Tatsache und die Aufgabe der Jurisprudenz, Baden-Baden, Nomos.

- 1994, Kritik der reinen Hermeneutik, Tübingen, Mohr.

AlChOURRÓn, C. E., y BulYGin, E., 1971: Normative Systems, N. York/Wien: Springer.

Alexy, R., 1989: Teoría de la argumentación jurídica [1978], trad. M. ATIENZA/I. EsPejo, Madrid, CEC.

- 1993: «Sobre las relaciones necesarias entre el Derecho y la Moral» [1989], trad. P. LARRAÑAGA, en Derecho y razón práctica, México, Fontamara, pp. 37-58.

Allen, R. J., 1991-92: «The Nature of Juridical Proof», Cardozo Law Review, 13: pp. 373-422. ARistóteles: Ética Nicomáquea, ed. de J. PAllí, Madrid, Gredos, 1993.

- Analíticos segundos, ed. M. CANDEL, Tratados de Lógica (Organon), Madrid, Gredos, 1988, II: pp. 313-440.

AtienZA, M., 1986: «Sobre la Jurisprudencia como técnica social. Respuesta a Roberto J. Vernengo», Doxa. Cuadernos de Filosofía del Derecho, 3: pp. 297-311.

- 1997: Contribución a una teoría de la legislación, Madrid, Civitas.

— 2004: «Argumentación y legislación», en A. MENÉNDEZ (ed.), La proliferación legislativa: un desafío para el Estado de Derecho, Madrid, Thomson-Civitas, pp. 89-112.

Aubenque, P., 1995: «The Twofold Natural Foundation of Justice According to Aristotle», en R. Heinaman (ed.), Aristotle and Moral Realism, Boulder, Westview, pp. 35-47.

BAYÓN, J. C., 2008: «Epistemología, moral y prueba de los hechos: hacia un enfoque no benthamiano», Ponencia presentada al XIV Congreso Italo-Español de Teoría del Derecho, Universitat de Girona, $21 \mathrm{pp}$.

Berman, H. J., 1977: «The Origins of Western Legal Science», Harvard Law Review, XC/5: pp. 894-943.

BETTI, E., 1990: Teoria generale della interpretazione [1955], Milán, Giuffrè, 2 vols.

BовBIO, N., 1950: Teoria della scienza giuridica, Torino, Giappichelli.

BOuvIER, H., 2004: «Reglas y razones subyacentes», Doxa, 27, pp. 393-424.

BRETONE, M., 1999: Tiempo y Derecho en la tradición europea [1994], trad. I. Rosas, México, FCE.

Bueno, G., 1995: ¿Qué es la ciencia?, Oviedo, Pentalfa.

CAlsamiglia, A., 1986: Introducción a la ciencia jurídica, Barcelona, Ariel.

CANARIS, C.-W., 1995: Función, estructura y falsación de las teorías jurídicas [1993], trad. D. BRÜCKNER y J. L. DE CASTRO, Madrid, Civitas.

CANNATA, C. A., 1989: Histoire de la jurisprudence européenne. La jurisprudence romaine, Turín, Giappichelli.

Cardín, A., 1988: «El efecto Rashomon en Etnología», en Tientos etnológicos, Madrid, Júcar, pp. 3-8. 
CoDERCH, P. S., 2004: «Técnica legislativa y teorías de la regulación», en A. MENÉNDEZ (ed.), La proliferación legislativa, cit., pp. 201-226.

Cruz, M., 1957: Historia de la filosofía española. Filosofía hispano-musulmana, Madrid, Asociación Española para el Progreso de las Ciencias, 2 vols.

DamašKa, M. R., 1986: The Faces of Justice and State Authority. A comparative Approach to the Legal Process, N. Haven, Yale UP.

EsSER, J., 1972: Vorverständnis und Methodenwahl in der Rechtsfindung, Frankfurt a.M., Athenäum.

Faigman, D. L., 1999: Legal Alchemy. The Use and Misuse of Science in the Law, New York, Freeman \& Co.

FARrell, M. D., 1979: La metodología del positivismo lógico. Su aplicación al Derecho, Buenos Aires: Astrea.

FERRAJOLI, L., 1995: Derecho y razón, [1989], trad. P. AnDRÉS, et al., Madrid, Trotta.

FERRER, J., 2005: Prueba y verdad en el Derecho, Madrid, Marcial Pons, 2. ${ }^{\text {a }}$ ed.

Foucault, M., 2005: Vigilar y castigar. Nacimiento de la prisión [1975], trad. A. Garzón, Madrid, Siglo XXI.

GAlgANO, F., 1990: Las instituciones de la economía capitalista [1974], trad. C. AlBORCH y M. Brosseta, Barcelona, Ariel.

GASCÓN, M., 1999: Los hechos en el Derecho. Bases argumentales de la prueba, Madrid, Marcial Pons.

GEERTZ, C., 1973: The Interpretation of Cultures, Nueva York, Basic Books.

Golan, T., 2004: Laws of Men and Laws of Nature: The History of Scientific Expert Testimony in England and America, Cambridge (Mass.), Harvard UP.

GONZÁLEZ LAGIER, D., 2003a: «Hechos y argumentos (Racionalidad epistemológica y prueba de los hechos en el proceso penal) (I)», Jueces para la Democracia, 46: pp. 17-26.

— 2003b: «Hechos y argumentos (Racionalidad epistemológica y prueba de los hechos en el proceso penal) (II)», Jueces para la Democracia, 47: pp. 35-50.

- 2006: «Argumentación y prueba judicial», en J. FERRER (et al.), Estudios sobre la prueba, México, UNAM, pp. 89-134.

GruTER, M., 1993: Rechtsverhalten. Biologische Grundlagen mit Beispielen aus dem Familienund Umweltrecht, Köln, O. Schmidt.

HaAck, S., 2005: «Trial and Error: The Supreme Court's Philosophy of Science», American Journal of Public Health, 95/1, pp. 66-73.

- 2008a: «What's Wrong with Litigation-Driven Science? An Essay in Legal Epistemology», Seton Hall Law Review, 38, pp. 1053-1083.

— 2008b: «Of Truth, In Science and in Law», Brooklyn Law Review, 73/3, pp. 985-1008.

Habermas, J., 2005: Facticidad y validez [19944], trad. M. Jiménez, Madrid, Trotta.

Hamburger, M., 1951: Morals and Law. The Growth of Aristotle's Legal Theory, New Haven, Yale UP.

Harenburg, J., 1986: Die Rechtsdogmatik zwischen Wissenschaft und Praxis, Stuttgart, Steiner.

Hegel, G. W. F., 1821: Principios de Filosofía del Derecho, trad. J. L. Vermal, Barcelona, Edhasa, 1988.

Huber, P. W., 1991: Galileo's Revenge: Junk Science in the Courtroom, New York, Basic Books.

IHERING, R. V., 2002: ¿Es el Derecho una ciencia? [1868], trad. F. FERnÁNDEZ-CreHUET, Granada, Comares.

JaSAnOFF, S., 1995; Science at the Bar: Science and Technology in American Law, Cambridge, Mass., Harvard UP. 
KANT, I., 1786: Metaphysische Anfangsgründe der Naturwissenschaft, Kants Werke AkademieTextausgabe, Berlín, W. de Gruyter \& Co., 1968 (reimp.), vol. IV: pp. 465-565.

- 1787: Kritik der reinen Vernunft, Kants Werke, cit., vol. III.

Kantorowicz, H., 1939: «The Quaestiones Disputatae of the Glossators», en Tijdschrift voor Rechtsgeschiedenis. Revue d'Histoire du Droit, 16, pp. 1-67.

- 1962: Rechtswissenschaft und Soziologie. Ausgewäblte Schriften zur Wissenschaftslebre, ed. de Th. Würtenberger, Karslruhe, C. F. Müller.

KASER, M., 1964: En torno al método de los juristas romanos [1962], trad. J. MiQUEL, Valladolid, Universidad de Valladolid.

Kaufmann, A., 1979: «Einige Bemerkungen zur Wissenschaftlichkeit der Rechtswissenschaft», en A. KAUfmann et al. (eds.), Festschrift für Bockelmann zum 70. Geburtstag am 7, Dezember 1978, München, Beck, pp. 67-73

Kelsen, H., 1960: Reine Rechtslebre, Wien, F. Deuticke (2. ${ }^{\text {e ed.). }}$

- 1941: «The Law as a Specific Social Technique», The University of Chicago Law Review, 9/1, pp. 75-97.

KiRCHMANN, J. H. von, 1949: El carácter a-científico de la llamada ciencia del Derecho [1847] trad. W. GoldschmidT en F. K. von SAVIGnY (et al.), La ciencia del Derecho, Buenos Aires, Losada, pp. 247-286.

KoschakeR, P., 1955: Europa y el Derecho romano [1947], trad. J. SANTA CRUZ, Madrid, Revista de Derecho Privado.

KunKEL, W., 1991: Historia del Derecho romano, trad. J. MiqueL, Barcelona, Ariel.

LA PIRA, G., 1935: «La genesi del sistema nella giurisprudenza romana. Il metodo», Studia et Documenta Historiae et Iuris, I/1, pp. 319-348.

- 1936-7: «La genesi del sistema nella giurisprudenza romana. Il concetto di scienza e gli strumenti della costruzione scientifica», Bullettino dell'Istituto di Diritto Romano «Vittorio Scialoja», XLIV, pp. 131-159.

LAnge, H., 1993: Die Anfänge der modernen Rechtswissenschaft. Bologna und das frühe Mittelalter, Stuttgart, Steiner.

LAPORTA, F. J., 2007: El imperio de la ley. Una visión actual, Madrid, Trotta.

LARENZ, K., 1966: Über die Unentbebrlichkeit der Jurisprudenz als Wissenschaft, Berlín, W. de Gruyter.

- 1996: «Concepción hermenéutica del método jurídico», Persona y Derecho, 35, pp. 11-38.

LOMBARDI, L., 1975: Saggio sul diritto giurisprudenziale, Milán, Giuffrè.

- 1981: Corso de Filosofía del Diritto, Padova, Cedam.

LuHMANN, N., 1983: Sistema jurídico y dogmática jurídica, trad. I DE OTTO, Madrid: CEC.

- 1987: Rechtssoziologie, Opladen, Westdeutscher Verlag (3. ${ }^{\mathrm{e}} \mathrm{ed}$. .).

LundstedT, A. V., 1932-36: Die Unwissenschaftlichkeit der Rechtswissenschaft, Berlín-Grunewald: W. Rothschild (vol. I); Berlín y Leipzig, Verlag für Staatswissenschaften und Geschichte GmbH (vol. II).

Llewellyn, K., 1941: «The Theory of Legal "Science"», North Carolina Law Review, 20: pp. $1-23$.

Mayer-Maly, T., 1972: Rechtswissenschaft, Darmstadt, Habel.

MerTON, R. K., 1985: «La estructura normativa de la ciencia» [1942], en La sociología de la ciencia, trad. N. Alberto, Madrid, Alianza, vol. II, pp. 355-368.

Monahan, J., y Walker, L., 20097: Social Sciences in Law. Cases and Materials, New York, Foundation Press. 
MonTANOS, M. E., 2004-06: «La planificación de los estudios jurisprudenciales en el marco de la soberanía estatal: soporte jurídico-doctrinal y control soberano», Ius Fugit. Revista interdisciplinar de estudios histórico-jurídicos, 13-14, pp. 13-38.

Mumford, L., 1987: Técnica y civilización [1934], trad. C. AzNAR, Madrid, Alianza.

Neumann, U., 1992: «La teoría de la ciencia jurídica», en A. Kaufmann y W. Hassemer (eds.), El pensamiento jurídico contemporáneo, Madrid, Debate, pp. 349-364.

Neurath, O., 1981: «Sociología en fisicalismo» [1931-2], en A. J. Ayer (ed.), El positivismo lógico, trad. L. Aldama et al., Madrid, FCE, pp. 287-322.

NINO, C. S., 1974: Consideraciones sobre la Dogmática jurídica, México, UNAM.

OAKley, J. B., 1985: «Sociobiology and the Law», en E. Bulygin et al. (eds.), Man, Law and Modern Forms of Life, Dordrecht, Reidel, pp. 43-54.

Oтте, G., 1971: Dialektik und Jurisprudenz. Untersuchungen zur Methode der Glossatoren, Frankfurt a.M., Klostermann.

Paredes Castañón, J. M., 2001: «Problemas metodológicos en la prueba del dolo», Anuario de Filosofía del Derecho, XVIII: pp. 67-93.

PEÑA, L., y Ausín, T. (2001), «La inferencia de hechos presuntos en la argumentación probatoria», Anuario de Filosofía del Derecho, XVIII: pp. 95-125.

Pound, R., 1910: «Law in Books and Law in Action» (1910), American Law Review, 44: pp. $12-$ 36.

- 2002: Social Control Through Law [1942], New Brunswick (N.J.), Transaction Publishers.

Radbruch, G., 1959: Filosofía del Derecho [1932], Madrid, Revista de Derecho Privado.

Ross, A., 1961: Hacia una ciencia realista del Derecho. Crítica del dualismo en el Derecho [1946], trad. J. BARBOZA, Buenos Aires, Abeledo-Perrot.

- 1994: Sobre el Derecho y la justicia [1953], trad. G. R. CARrió, Buenos Aires, Eudeba (reimp.).

Sampaio Ferraz, T., 1978: Funçao social da dogmática jurídica, Sao Paulo, Revista dos Tribunais.

SANDERS, J., 2009: «Science, Law, and the Expert Witness», Law and Contemporary Problems, 72, pp. 63-90.

SavignY, E. von, 1976: «Methodologie der Dogmatik: Wissenschaftstheoretische Fragen», en U, Neumann et al., Juristische Dogmatik und Wissenschaftstheorie, München, Beck, pp. 7-13.

SCHLAPP, Th., 1989: Theorienstrukturen und Rechtsdogmatik. Ansätze zu einer strukturalistischen Sicht juristischer Theoriebildung, Berlín, Duncker \& Humblot.

SCHRÖDER, J., 1981: Wissenschaftstheorie und Lebre der «praktischen Jurisprudenz» auf deutschen Universitäten an der Wende zum 19. Jabrhundert, Frankfurt a. M., V. Klostermann.

- 2001: Recht als Wissenschaft. Geschichte der juristischen Methode vom Humanismus bis zur bistorischen Schule (1500-1850), München, Beck.

ScHUlZ, F., 1961: Geschichte der römischen Rechtswissenchaft, Weimar, Hermann Böhlaus.

SchweBER, H.: «The "Science" of Legal Science: The Model of the Natural Sciences in Nineteenth-Century American Legal Education», Law and History Review, 17/3 (disponible en http://www.historycooperative.org/journals/lhr/17.3/schweber.html).

SHINER, R. A., 1994: «Aristotle's Theory of Equity», Loyola of Los Angeles Law Review, 27/4, pp. $1245-1264$.

SimON, D., 1988: «Jurisprudenz und Wissenschaft», Rechtshistorisches Journal, 7, pp. 141-156.

STEPHANITZ, D. von, 1970: Exakte Wissenschaft und Recht. Der Einfluß von Naturwissenschaft und Mathematik auf Rechtsdenken und Rechtswissenschaft in zweieinhalb Jabrtausenden. Ein historischer Grundriß, Berlín, W. de Gruyter. 
TARUfFO, M., 2002: La prueba de los hechos [1992], trad. J. FerRer, Madrid, Trotta.

— 2006: «La prueba científica en el proceso civil», trad. M. FERNÁNDEZ y D. GONZÁLEZ. en J. FERRER (et al.), Estudios sobre la prueba, cit., pp. 135-186.

TRIBE, L., 1971: «Trial by Mathematics: Precision and Ritual in the Legal Process», Harvard Law Review, 84, pp. 1329-1393.

TRIPP, D., 1983: Der Einfluß des naturwissenschaftlichen, philosophischen und historischen Positivismus auf die deutsche Rechtslebre im 19. Jabrbundert, Berlín, Duncker \& Humblot.

TwINING, W., 2006: Rethinking Evidence. Exploratory Essays, New York, Cambridge UP.

Vega, J., 2000: La idea de ciencia en el Derecho, Oviedo, Pentalfa.

VIeHWeg, Th., 1991: Tópica y Filosofía del Derecho, trad. J. MALEM, Barcelona, Gedisa.

VILLA, V., 1994: Teorie della scienza giuridica e teorie delle scienze naturali. Modelli ed analogie, Milán, Giuffrè.

WeBER, M., 1973: Gesammelte Aufsätze zur Wissenschaftslebre, J. WinCKELMANN (ed.), Tübingen, Mohr.

- 1993: Economía y sociedad [1922], trad. J. MedinA et al., Madrid, FCE.

Woocher, F., 1977: «Did Your Eyes Deceive You? Expert Psychological Testimony on the Unrealiability of Eyewittness Identification», Stanford Law Review, 29/5, pp. 969-1030.

WRight, G. H. von, 1987: Explicación y comprensión [1971], trad. L. VEGA, Madrid, Alianza. 